\title{
Rapid discovery of chemical constituents and absorbed components in rat serum after oral administration of Fuzi-Lizhong pill based on high-throughput HPLC-Q-TOF/MS analysis
}

Zhen Zhang ${ }^{1 \dagger}$, Maoyuan Jiang ${ }^{1 \dagger}$, Xinyi Wei ${ }^{1}$, Jinfeng Shi ${ }^{1}$, Zhao Geng ${ }^{2}$, Shasha Yang ${ }^{1}$, Chaomei Fu ${ }^{1 *}$ (D) and Li Guo ${ }^{1 *}$

\begin{abstract}
Background: Fuzi-Lizhong pill (FZLZP), which was first recorded in the Classic-“Taiping Huimin Heji Ju Fang" of the Song Dynasty, has been widely used to treat gastrointestinal disease in clinic for thousands of years in China. However, an in-depth understanding of the chemical constituents of FZLZP and its potential bioactive constituents is lacking.

Methods: A simple, sensitive and selective method of high-performance liquid chromatography coupled with quadrupole-time-of-flight high-definition mass spectrometry (HPLC-Q-TOF/MS) and automated data analysis (Agilent MassHunter Qualitative Analysis B.06.00 Workstation Software) was developed to simultaneously identify the chemical constituents of FZLZP and the absorbed prototypes as well as the metabolites in rat serum after the oral administration of FZLZP.
\end{abstract}

Results: Sixty-seven compounds, including alkaloids, flavonoids, triterpenes, gingerols, phenylpropanoids and volatile oil, in the FZLZP extract were tentatively characterized by comparing the retention time and mass spectrometry data and retrieving the reference literatures. Additionally, 23 prototype compounds and 3 metabolites in the rat serum samples were identified after oral administration of FZLZP, which might be the potential active components in vivo. In addition, the absorption of alkaloids decreased when Aconitum carmichaeli Debx. was in the form of combined application as a prescription compared to when it was in the form of herb powder.

Conclusions: Herein, the chemical constituent in vitro and the absorbed compounds in the serum of a traditional Chinese formula, Fuzi-Lizhong pill, were fully characterized using a rapid and comprehensive analysis approach based on high-performance liquid chromatography combined with quadrupole time-of-flight mass spectrometry coupled to MassHunter Qualitative Analysis software data processing approach. The results provide helpful chemical information on FZLZP for further pharmacology and active mechanism research. In view of the bioactive constitutes that basically were derived from these absorbed compounds in vivo, this work could provide a useful strategy to explore the bioactive substances of traditional Chinese medicine.

\footnotetext{
*Correspondence: chaomeifu@126.com; gli64@sina.com

${ }^{\dagger} \mathrm{ZZ}$ and MJ contributed equally to this work.

${ }^{1}$ The Ministry of Education Key Laboratory of Standardization of Chinese

Herbal Medicine, State Key Laboratory Breeding Base of Systematic

Research, Development and Utilization of Chinese Medicine Resources,

College of Pharmacy, Chengdu University of Traditional Chinese

Medicine, Chengdu 611137, China

Full list of author information is available at the end of the article
}

(c) The Author(s) 2019. This article is distributed under the terms of the Creative Commons Attribution 4.0 International License (http://creativecommons.org/licenses/by/4.0/), which permits unrestricted use, distribution, and reproduction in any medium, provided you give appropriate credit to the original author(s) and the source, provide a link to the Creative Commons license, and indicate if changes were made. The Creative Commons Public Domain Dedication waiver (http://creativecommons.org/ publicdomain/zero/1.0/) applies to the data made available in this article, unless otherwise stated. 
Keywords: Fuzi-Lizhong pill, Chemical constituents, Bioactive compounds, Metabolites, Traditional Chinese herbal medicine, High-performance liquid chromatography-electrospray ionization/quadrupole-time-of-flight high definition mass spectrometry

\section{Background}

Fuzi-Lizhong pill (FZLZP) is a popular Traditional Chinese medicine pill that was originally described in the Classic "Taiping Huimin Heji Ju F/ang" of the Song Dynasty (year 1102 by the Western calendar). It is composed of five herbal medicines, including Aconitum carmichaeli Debx. (Fuzi), Codonopsis pilosula (Franch.) Nannf. (Dangshen), Atractylodes macrocephala Koidz. (Baizhu), Glycyrrhiza uralensis Fisch. (Gancao) and Zingiber officinale Rosc. (Ganjiang). FZLZP is famous for warming the middle-jiao and tonifying the spleen and is used to treat spleen yang deficiency syndrome including enteritis, chronic diarrhoea, irritable bowel syndrome, abdominal pain, vomiting and spasm, peripheral chill, etc. [1-7]. Modern pharmacological research shows that FZLZP possesses a variety of pharmacological activities, including an increase in adaptive thermogenesis, pain relief, anti-inflammation, and spasmolytic benefits [8-15]. Although pharmacological activities of FZLZP have been extensively studied, very little is known about its systematic chemical constituents, and the bioactive compounds that account for its therapeutic effects remain unclear.

In our previous research, we focused on the dissolution behaviour of FZLZP in vitro and the results showed that some constituents in Aconitum carmichaeli Debx. and Glycyrrhiza uralensis Fisch., such as benzoylaconine, liquiritin and glycyrrhizic acid, were dissolved well in vitro [16-18]. While FZLZP has the so-called active ingredients, there are no empirical data to prove their effectiveness as bioactive compounds. According to the theory of serum pharmacochemistry, while there are multiple components in herbs, only compounds that are absorbed into the blood have the possibility of showing pharmacological bioactivities [19-24]. Therefore, simultaneous identification of systematic chemical constituents in vitro and potential active components in the blood of FZLZP are indispensable.

It was reported that the main components in Aconitum carmichaeli Debx. are monoester diterpenoid alkaloids (MDAs) and diester diterpenoid alkaloids (DDAs), which are toxicity and efficacy compounds and should be highly concerned [21]. Due to the toxicity, Fuzi is usually used in combination with other herbs as a prescription. Some researcher considered the combination to cause the reduction of the absorption of toxic compounds [21, 25]. As a typical combination, however, there are no detailed studies of this mechanism and the compound variations of FZLZP. The strategy of serum thermochemistry can provide us the accurate qualitative and the preliminary quantitative information for exploring the quantitative change of alkaloids and toxicity reducing mechanism.

Currently, LC-MS is widely applied for the analysis of herbal constituents in vitro and in vivo because of its superior sensitivity, selectivity and ability to conclusively identify the compounds [26-29]. In this study, an approach of high-performance liquid chromatography (HPLC) quadrupole time-of-flight mass spectrometry (QTOF-MS) based on serum pharmacochemistry was developed to identify the phytochemical constituents of FZLZP and multiple absorbed components in rat serum.

\section{Methods}

The Minimum Standards of Reporting Checklist contains details of the experimental design, and statistics, and resources used in this study (Additional file 1).

\section{Chemicals and materials}

Nine reference compounds were obtained from Sichuan Victor Biological Technology Co. Ltd. (Chengdu China). HPLC grade Ethanol, formic acid and methanol were obtained from Fisher (ThermoFisher Scientific Inc, Waltham, MA, USA). Deionised water $(18 \mathrm{M} \Omega$ ) was prepared by distilled water through a Milli-Q system (Millipore, Milford, MA, USA). Fuzi (No. 1703003), Dangshen (No. 1705003), Baizhu (No. 1704088), Ganjiang (No. 1703060) and Gancao (No. 1703034) were purchased from Sichuan Neautus Traditional Chinese Medicine Co., Ltd. (Chengdu China) and were authenticated by Prof. Jin Pei, Department of Pharmacognosy of Chengdu University of Chinese Medicine.

\section{Preparation of FZLZP}

Fuzi, Ganjiang, Dangshen, Baizhu and Gancao were ground into fine powers and weighed according to the instructions recorded in Chinese Pharmacopoeia (2015 edition) and mixed well. Honey was heated at 116$118^{\circ} \mathrm{C}$ until bright yellow uniform bubbles appeared on the surface and the honey became sticky. Mixed power and thermal refined honey were mixed at a ratio of 1:0.8 and were made into FZLZP (there is $0.153 \mathrm{~kg}$ crude aconite for every $1 \mathrm{~kg}$ FZLZP). 
Preparation of FZLZP extract samples for LC/MS analysis FZLZP (1.5 g) was weighed and reflux-extracted with $50 \mathrm{~mL} 70 \%$ ethanol for $1 \mathrm{~h}$. Then, the filtered supernatant sample was rotary evaporated at $40{ }^{\circ} \mathrm{C}$ to a concentration of $15 \mathrm{~mL}$, and was centrifuged at 5000 revolutions $/ \mathrm{min}$ $(\mathrm{rpm})$ for $5 \mathrm{~min}$. The solution was filtered through a $0.22-$ $\mu \mathrm{m}$ membrane for further analysis.

\section{Animal handling and serum sample preparation}

Eighteen male Sprague-Dawley rats $(200 \pm 20 \mathrm{~g})$ were obtained from the Sichuan Dashuo Biotechnology Co., Ltd. and were randomly divided into three groups of 6 rats each (group A, FZLZP group for dosed rat serum; group B, Fuzi powder (FZP) group for dosed rat serum; group $\mathrm{C}$, control group for blank rat serum). The animal facilities and protocols conformed to the Care and Use of Laboratory Animals published by the National Institutes of Health. The experiment was approved by the ethical committee of Chengdu University of TCM (No.20161105). The rats were housed in an animal room with a controlled environment $\left(20-25{ }^{\circ} \mathrm{C}, 65-69 \%\right.$ relative humidity, $12 \mathrm{~h}$ dark-light cycle), and were given water and fed normal food for 1 week before the experiment. All animals were fasted overnight before the experiments and had free access to water.

The FZLZP was dissolved in 0.5\% CMC-Na and were grinded to prepare the FZLZP suspension (150 mg crude $\mathrm{drug} / \mathrm{mL}$ ). Fuzi powder was dissolved in $0.5 \% \mathrm{CMC}-\mathrm{Na}$ to prepare the FZPsuspension (23 $\mathrm{mg}$ crude drug $/ \mathrm{mL}$, the concentration of FuZi was calculated by the ratio in FZLZP). Group A was intragastric administration $1.5 \mathrm{~g} /$ $\mathrm{kg}$ body weight of FZLZP suspension for 3 days. Group $\mathrm{B}$ was intragastric administration $0.23 \mathrm{~g} / \mathrm{kg}$ body weight of FZP suspension for 3 days. Group $C$ was intragastric administration with an equivalent volume of $0.5 \% \mathrm{CMC}$ $\mathrm{Na}$. Blood samples were collected from the abdominal aorta $45 \mathrm{~min}$ after oral administration on the 3rd day and were placed at room temperature for $1 \mathrm{~h}$ until solidification. Then, samples were centrifuged at $3000 \mathrm{rpm}$ for $10 \mathrm{~min}$ at $4{ }^{\circ} \mathrm{C}$. All samples were stored at $-80{ }^{\circ} \mathrm{C}$ until analysis. Three times methanol was added to the $2 \mathrm{~mL}$ serum samples, vortexed and then, centrifuged at $12,000 \mathrm{rpm}$ for $20 \mathrm{~min}$. The supernatant was dried with nitrogen gas. The residue was redissolved in $50 \mu \mathrm{L}$ methanol, vortexed and then, centrifuged at 12,000 rpm for $20 \mathrm{~min}$, and the filtrate was used as the LC/MS sample. $10 \mu \mathrm{L}$ aliquot was injected for HPLC/MS analysis.

\section{HPLC-QTOF-MS analysis condition}

Chromatographic analysis was performed in an Agilent 1290 HPLC system controlled with MassHunter Workstation Software (V B.05.00, Agilent Technologies Inc,
Santa Clara, CA, USA). Samples were separated on an Agilent $\mathrm{HC}^{-\mathrm{C}_{18}}$ column $(4.6 \times 250 \mathrm{~mm}, 5.0 \mu \mathrm{m}$, Agilent Technologies Inc.) held at $35{ }^{\circ} \mathrm{C}$ and the flow rate was $1.0 \mathrm{~mL} / \mathrm{min}$ with the injection volume of $10 \mu \mathrm{L}$. The mobile phase consisted of $0.1 \%$ formic acid-water $(\mathrm{v} / \mathrm{v}$, A) and methanol (B). The optimal gradient elution programme was as follows: $0-15 \mathrm{~min}, 95-70 \% \mathrm{~A} ; 15-30 \mathrm{~min}$, $70-48 \%$ A; 30-45 min, $48-25 \%$ A; 45-48 min, $25-15 \%$ A; 48-55 $\mathrm{min}, 15-2 \% \mathrm{~A}$; and $55-65 \mathrm{~min}, 2-2 \% \mathrm{~A}$.

\section{Mass spectrometry conditions}

Mass spectrometry was performed using an Agilent 6540 QTOF-MS (Agilent Corp., USA) equipped with a Dual AJS electrospray ionization (ESI) source, and the following operating parameters were used: positive mode, drying gas (nitrogen, $\mathrm{N}_{2}$ ); flow rate, $8.0 \mathrm{~L} / \mathrm{min}$; gas temperature, $325^{\circ} \mathrm{C}$; nebulizer, 40 psig; sheath gas temperature, $350{ }^{\circ} \mathrm{C}$; sheath gas flow, $11 \mathrm{~L} / \mathrm{min}$; capillary voltage, $4000 \mathrm{~V}$; skimmer, $65 \mathrm{~V}$; OCT 1 RF Vpp, $750 \mathrm{~V}$; fragmentor, $110 \mathrm{~V}$. The sample collision energy was set at 10,20 , 30 and $40 \mathrm{~V}$. All the operations, acquisition, and analyses of data were controlled by Agilent LCMS-QTOF Mass Hunter Acquisition Software Ver. B.06.00 (Agilent Technologies Inc.) and operated under Mass Hunter Workstation Software Version B.06.00 (Agilent Technologies Inc.).

\section{Establishment of FZLZP database}

By searching databases, such as PubMed of the US National Library Medicine and the National Institutes of Health, SciFinder Scholar of American Chemical Society and the Chinese National Knowledge Infrastructure (CNKI) of Tsinghua University, all components reported in the literature on Aconitum carmichaeli Debx., Codonopsis pilosula (Franch.) Nannf., Atractylodes macrocephala Koidz., Glycyrrhiza uralensis Fisch. and Zingiber officinale Rosc. were summarized in an Agilent PCDL software Ver. B.06.00 (Agilent Technologies Inc.) to establish a database, which includes the name, molecular formula, chemical structure and literatures of each published known compound.

\section{Results}

Characterization of chemical constituents from FZLZP

Using the optimal conditions described above, all information on the MS data that was obtained from the robust HPLC-TOF-MS analysis, indicated the retention time and precise molecular mass and provided the MS/ MS data. The protonated molecular weights of all target compounds were calculated within an error of $5 \mathrm{ppm}$. The base peak chromatogram (BPC) of the FZLZP extract sample in positive and negative ion modes are shown in Fig. 1A, and the data were processed by 
A

A

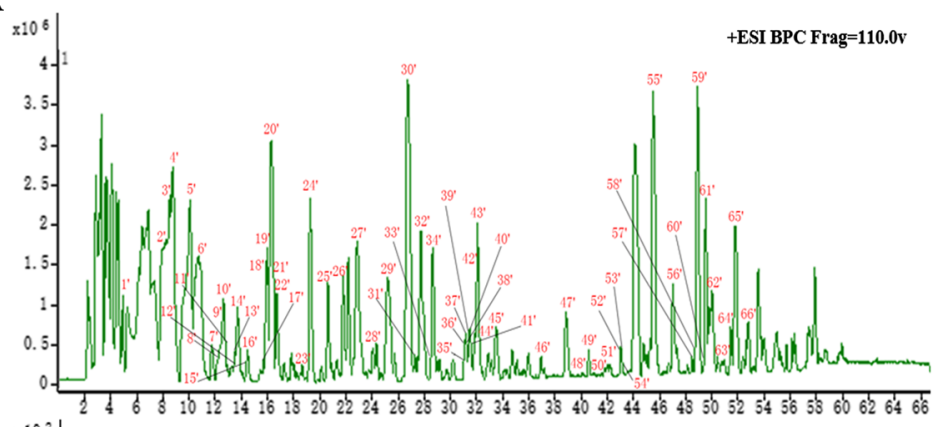
$x 10^{2}$

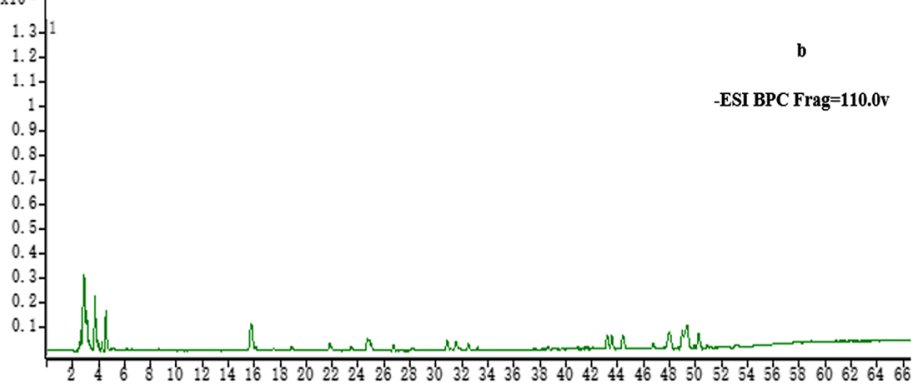

B
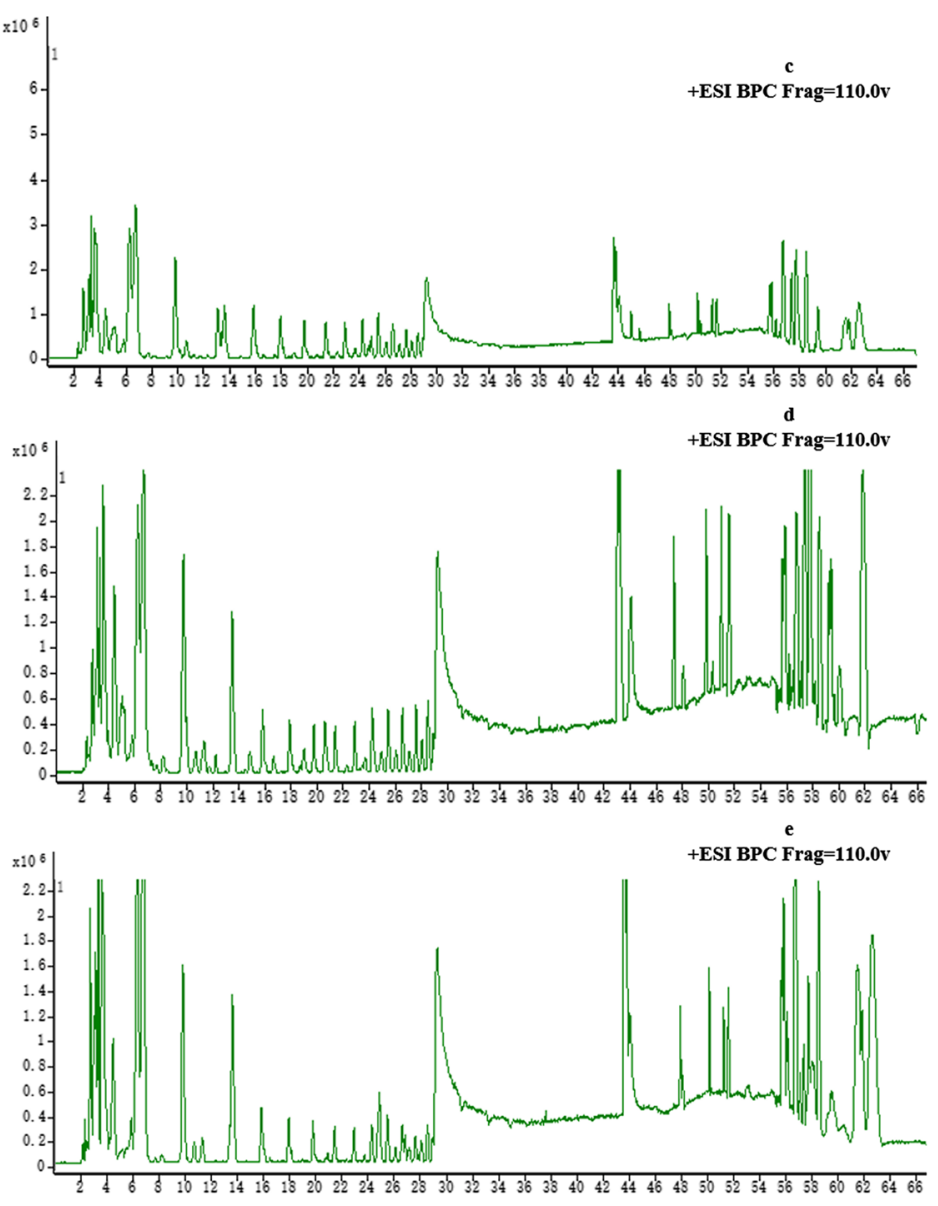

Fig. 1 The HPLC-ESI/QTOF/MS BPC chromatograms (A FZLZP extract samples: a in positive mode, $\mathbf{b}$ in negative mode; B Serum samples: c controlled serum in positive mode, $\mathbf{d}$ dosed FZLZP serum in positive mode, e dosed FZP serum in positive mode.) 
the Agilent MassHunter Qualitative Analysis B.06.00 Workstation Software with the "find compounds by molecular formula" tool. A total of 73 peaks were obtained, and 67 compounds were identified or tentatively characterized by comparing the $t_{R}$ values and the MS fragment characteristics of the compounds.
The reference standards are summarized in Table 1 and their fragmentation mechanism are proposed in Fig. 2. The compounds in FZLZP which are identified by the reference standards are summarized and marked in Table 2. For example, reference standards (RS) 1 liquiritigenin in Table 1 were detected in the positive ion mode at the Rt in $24.843 \mathrm{~min}$ with the $\mathrm{m} / z$ of $257.0809\left(\mathrm{C}_{15} \mathrm{H}_{13} \mathrm{O}_{4}\right)$. Its

Table 1 Retention time, $\mathrm{m} / \mathrm{z}$ values of ions of reference standards

\begin{tabular}{|c|c|c|c|c|c|c|c|c|}
\hline \multirow{2}{*}{$\begin{array}{l}\text { Peak } \\
\text { no. }\end{array}$} & \multirow{2}{*}{$\begin{array}{l}\text { Rt } \\
(\min )\end{array}$} & \multirow[t]{2}{*}{ Systematic name } & \multirow{2}{*}{$\begin{array}{l}\text { Molecular } \\
\text { formula }\end{array}$} & \multicolumn{2}{|l|}{$[\mathrm{M}+\mathrm{H}]^{+}$} & \multicolumn{2}{|l|}{$[\mathrm{M}+\mathrm{Na}]^{+}$} & \multirow[t]{2}{*}{ Fragmentations (m/z) } \\
\hline & & & & $\begin{array}{l}\text { Measured } \\
\text { mass }(\mathrm{m} / \mathrm{z})\end{array}$ & $\begin{array}{l}\text { Error } \\
\text { (ppm) }\end{array}$ & $\begin{array}{l}\text { Measured } \\
\text { mass }(\mathrm{m} / \mathrm{z})\end{array}$ & Error (ppm) & \\
\hline 1 & 24.843 & Liquiritigenin & $\mathrm{C}_{15} \mathrm{H}_{12} \mathrm{O}_{4}$ & 257.0809 & 0.3890 & & & $\begin{array}{l}257.0809\left[\mathrm{M}+\mathrm{H}^{+}{ }^{\prime}\right. \\
239.0698\left[\mathrm{M}+\mathrm{H}_{-}-\mathrm{H}_{2} \mathrm{O}\right]^{+}, \\
137.0234\left[\mathrm{C}_{7} \mathrm{H}_{4} \mathrm{O}_{3}+\mathrm{H}^{+}\right]^{\prime} \\
121.0293\left[\mathrm{C}_{8} \mathrm{H}_{8} \mathrm{O}+\mathrm{H}^{+}{ }^{\prime}\right. \\
120.0721\left[\mathrm{C}_{7} \mathrm{H}_{4} \mathrm{O}_{3}+\mathrm{H}-\mathrm{OH}\right]^{+}\end{array}$ \\
\hline 2 & 27.507 & Benzoylmesaconine & $\mathrm{C}_{31} \mathrm{H}_{43} \mathrm{NO}_{10}$ & 590.2952 & -1.3553 & - & - & $\begin{array}{l}590.2952[\mathrm{M}+\mathrm{H}]^{+} \\
572.2832\left[\mathrm{M}+\mathrm{H}_{-}-\mathrm{H}_{2} \mathrm{O}\right]^{+} \\
558.2683\left[\mathrm{M}+\mathrm{H}-\mathrm{CH}_{3} \mathrm{OH}\right]^{+} \\
540.2580\left[\mathrm{M}+\mathrm{H}-\mathrm{CH}_{3} \mathrm{OH}-\right. \\
\left.\mathrm{H}_{2} \mathrm{O}\right]^{+}\end{array}$ \\
\hline 3 & 28.228 & Benzoylaconine & $\mathrm{C}_{32} \mathrm{H}_{45} \mathrm{NO}_{10}$ & 604.3130 & 2.3167 & - & - & $\begin{array}{l}604.3130[\mathrm{M}+\mathrm{H}]^{+} \\
586.2995\left[\mathrm{M}+\mathrm{H}-\mathrm{H}_{2} \mathrm{O}\right]^{+} \\
572.2852\left[\mathrm{M}+\mathrm{H}-\mathrm{CH}_{3} \mathrm{OH}\right]^{+} \\
554.2735\left[\mathrm{M}+\mathrm{H}-2 \mathrm{H}_{2} \mathrm{O}\right]^{+} \\
540.2577\left[\mathrm{M}+\mathrm{H}-\mathrm{CH}_{3} \mathrm{OH}\right]^{+} \\
522.2475\left[\mathrm{M}+\mathrm{H}-2 \mathrm{CH}_{3} \mathrm{OH}-\right. \\
\left.\mathrm{H}_{2} \mathrm{O}\right]^{+}\end{array}$ \\
\hline 4 & 29.152 & Benzoylhypaconine & $\mathrm{C}_{31} \mathrm{H}_{43} \mathrm{NO}_{9}$ & 574.3003 & -1.3930 & - & - & $\begin{array}{l}\text { 574.3003[M+H]+, } \\
\quad 542.2741\left[\mathrm{M}+\mathrm{H}-\mathrm{CH}_{3} \mathrm{OH}\right]^{+} \\
524.2615[\mathrm{M}+\mathrm{H}- \\
\left.\mathrm{CH}_{3} \mathrm{OH}-\mathrm{H}_{2} \mathrm{O}\right]^{+} \\
510.2477\left[\mathrm{M}+\mathrm{H}-2 \mathrm{CH}_{3} \mathrm{OH}\right]^{+}\end{array}$ \\
\hline 5 & 31.663 & Mesaconitine & $\mathrm{C}_{33} \mathrm{H}_{45} \mathrm{NO}_{11}$ & 632.3064 & -0.1582 & - & - & $\begin{array}{l}632.3064[\mathrm{M}+\mathrm{H}]^{+} \\
600.2787\left[\mathrm{M}+\mathrm{H}-\mathrm{CH}_{3} \mathrm{OH}\right]^{+} \\
572.2853[\mathrm{M}+\mathrm{H}-\mathrm{AcOH}]^{+} \\
540.2594[\mathrm{M}+\mathrm{H}-\mathrm{AcOH}- \\
\left.\mathrm{CH}_{3} \mathrm{OH}\right]^{+}, 512.2637[\mathrm{M}+\mathrm{H}- \\
\left.\mathrm{AcOH}-\mathrm{CH}_{3} \mathrm{OH}-\mathrm{CO}\right]^{+}\end{array}$ \\
\hline 6 & 39.648 & Isoliquiritigenin & $\mathrm{C}_{15} \mathrm{H}_{12} \mathrm{O}_{4}$ & 257.0809 & 0.3890 & & & $\begin{array}{l}257.0809[\mathrm{M}+\mathrm{H}]^{+}, \\
239.0692\left[\mathrm{M}+\mathrm{H}_{-}-\mathrm{H}_{2} \mathrm{O}\right]^{+}, \\
137.0235\left[\mathrm{C}_{7} \mathrm{H}_{4} \mathrm{O}_{3}+\mathrm{H}^{+}\right]^{\prime} \\
121.0287\left[\mathrm{C}_{8} \mathrm{H}_{8} \mathrm{O}+\mathrm{H}^{+}{ }^{\prime}\right. \\
120.0514\left[\mathrm{C}_{7} \mathrm{H}_{4} \mathrm{O}_{3}+\mathrm{H}-\mathrm{OH}\right]^{+}\end{array}$ \\
\hline 7 & 48.854 & Atractylenolide II & $\mathrm{C}_{15} \mathrm{H}_{20} \mathrm{O}_{2}$ & 233.1538 & 0.8578 & & & $\begin{array}{l}233.1538[\mathrm{M}+\mathrm{Na}]^{+}, \\
215.1440\left[\mathrm{M}+\mathrm{Na}-\mathrm{H}_{2} \mathrm{O}\right]^{+}, \\
187.1484\left[\mathrm{M}+\mathrm{Na}-\mathrm{CH}_{2} \mathrm{O}_{2}\right]^{+}, \\
159.1165\left[\mathrm{M}+\mathrm{Na}-\mathrm{CH}_{2} \mathrm{O}_{2}-\right. \\
\left.\mathrm{C}_{2} \mathrm{H}_{4}\right]^{+}, 145.101[\mathrm{M}+\mathrm{Na}- \\
\left.\mathrm{CH}_{2} \mathrm{O}_{2}-\mathrm{C}_{3} \mathrm{H}_{6}\right]^{+} \\
131.0856\left[\mathrm{M}+\mathrm{Na}-\mathrm{CH}_{2} \mathrm{O}_{2}-\mathrm{C}_{4} \mathrm{H}_{8}\right]^{+} \\
105.0702\left[\mathrm{M}+\mathrm{Na}-\mathrm{CH}_{2} \mathrm{O}_{2}-\right. \\
\left.\mathrm{C}_{4} \mathrm{H}_{8}-\mathrm{C}_{2} \mathrm{H}_{2}\right]^{+}\end{array}$ \\
\hline 8 & 49.134 & Glycyrrhizic acid & $\mathrm{C}_{42} \mathrm{H}_{62} \mathrm{O}_{16}$ & & & 845.3947 & 2.0109 & $\begin{array}{l}\text { 845.3947[M+Na }]^{+} \\
669.3614[\mathrm{M}+\mathrm{Na}-(\mathrm{GluA}- \\
\left.\left.\mathrm{H}_{2} \mathrm{O}\right)\right]^{+}\end{array}$ \\
\hline 9 & 55.125 & Glycyrrhetinic acid & $\mathrm{C}_{30} \mathrm{H}_{46} \mathrm{O}_{4}$ & 471.3458 & -2.3337 & & & 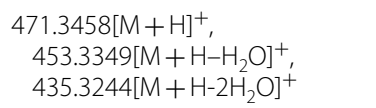 \\
\hline
\end{tabular}


$\mathbf{a}$

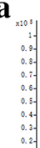

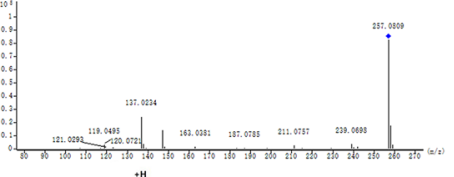

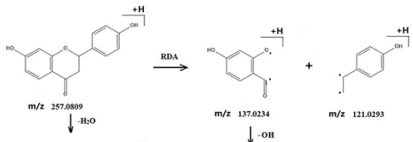

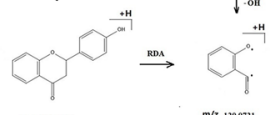

c
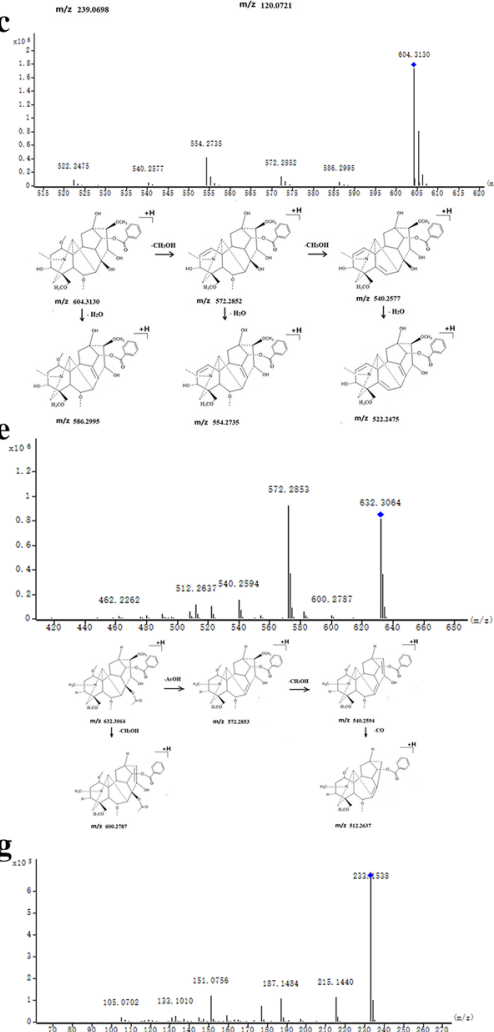

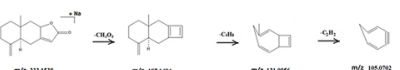

bas. $y$
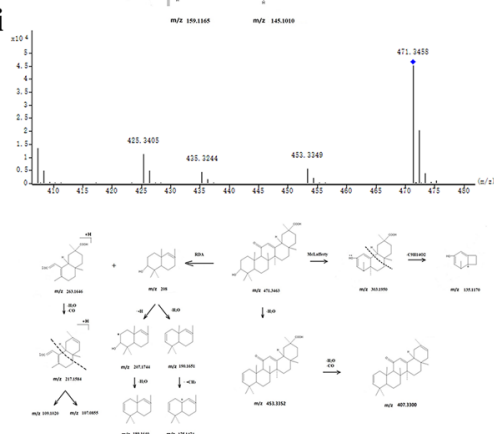

b

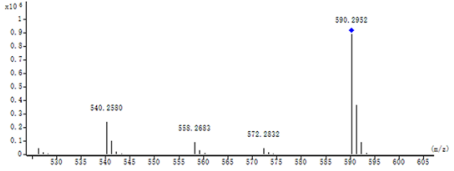

d
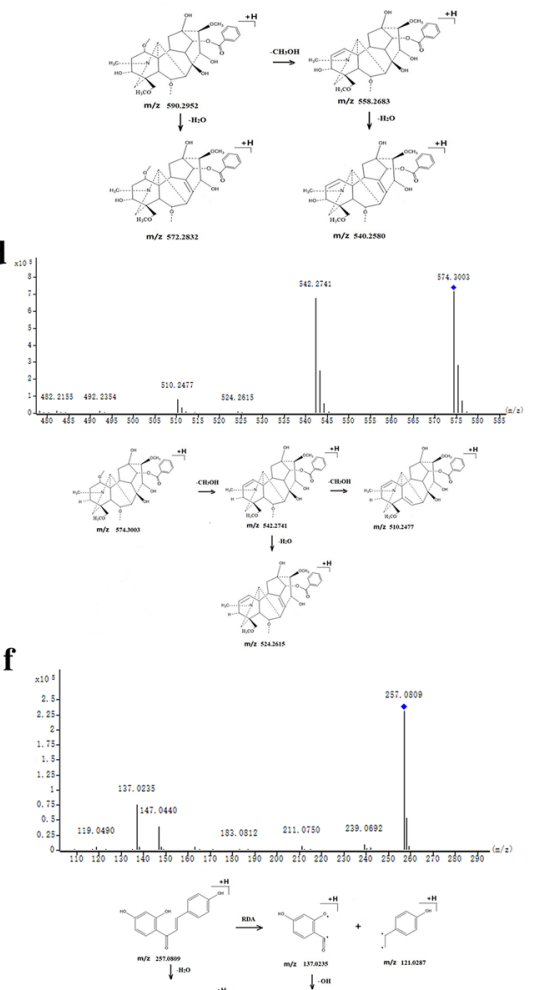

h
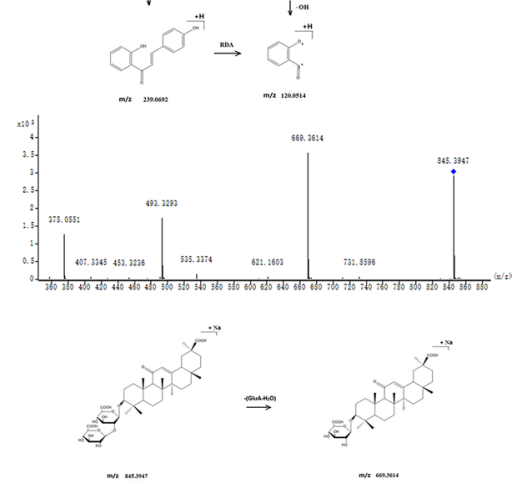

Fig. 2 The mass fragment and fragmentation pathway of a Liquiritigenin, b Benzoylmesaconine, c Benzoylaconine, d Benzoylhypaconine, e mesaconitine, $\mathbf{f}$ Isoliquiritigenin, $\mathbf{g}$ Atractylenolide II, $\mathbf{h}$ Glycyrrhizic acid, $\mathbf{i}$ Glycyrrhetinic acid 


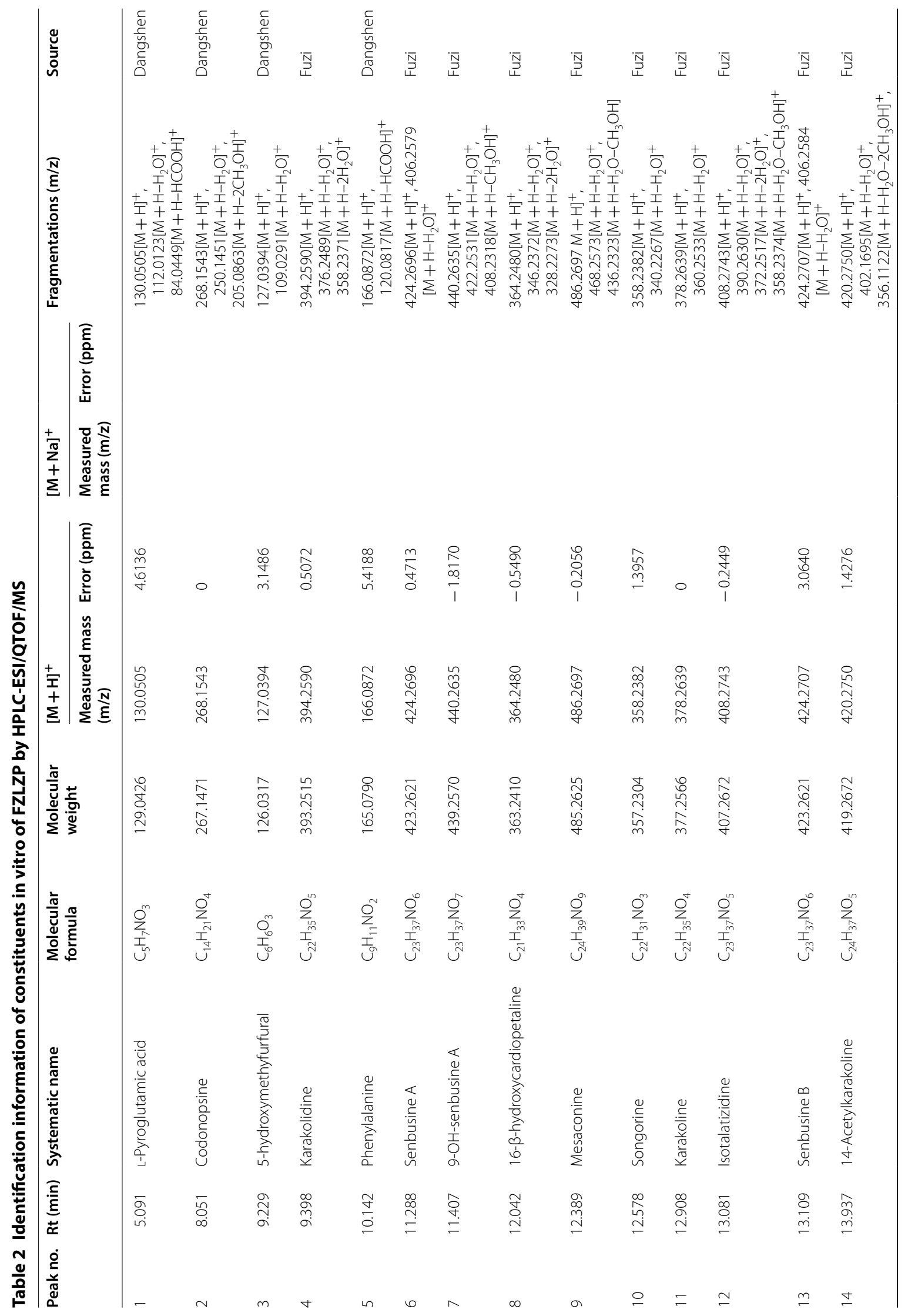




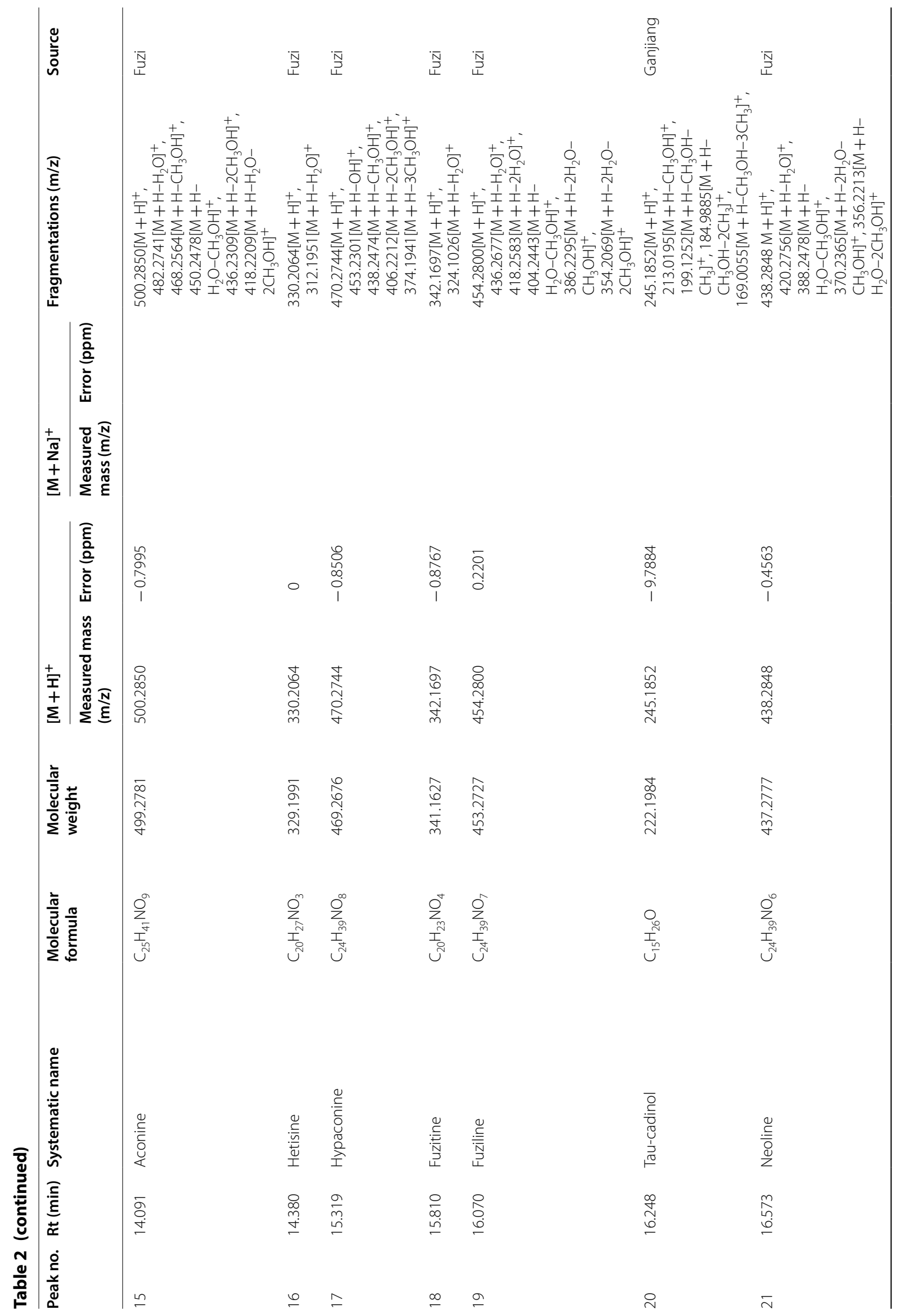




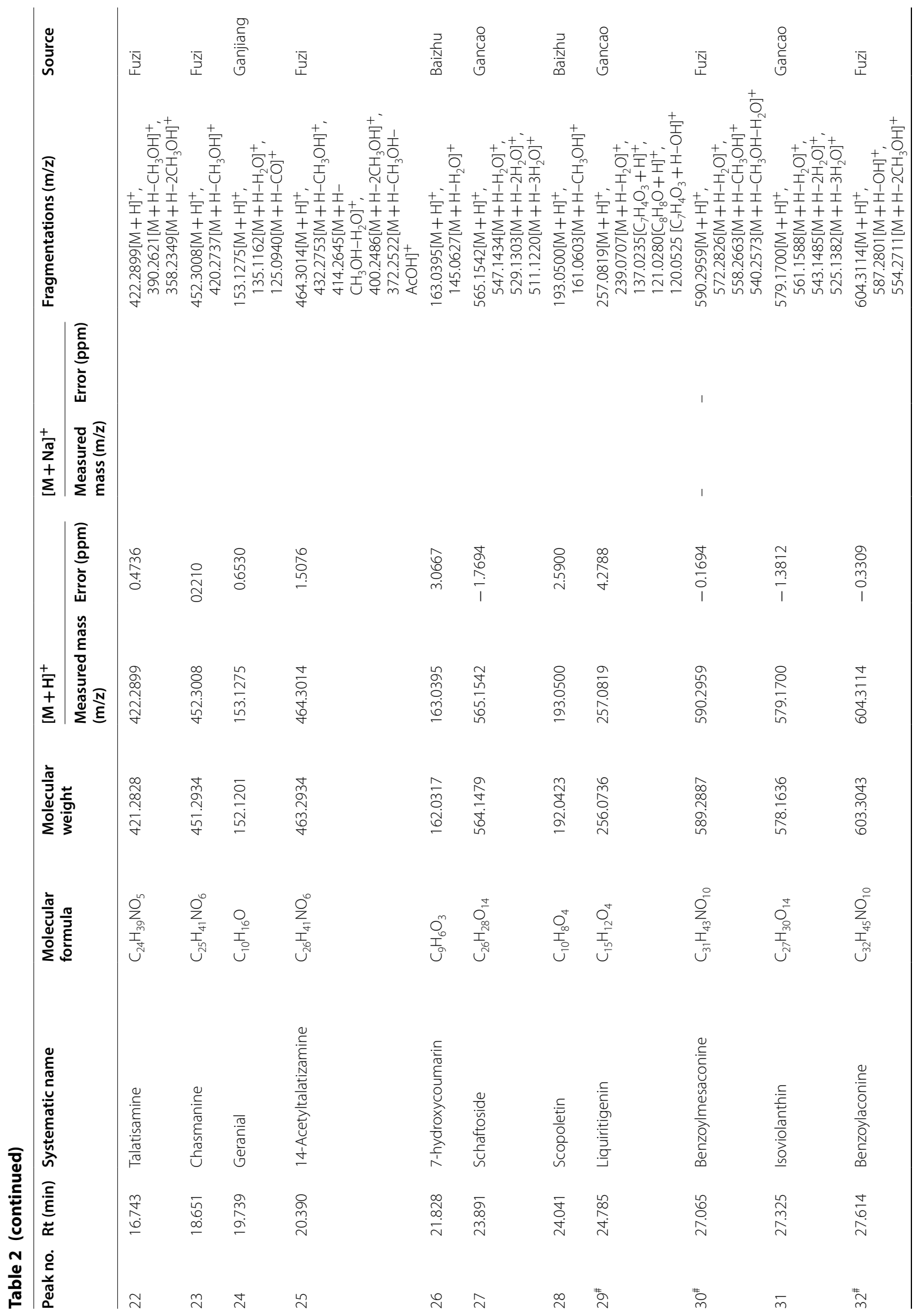




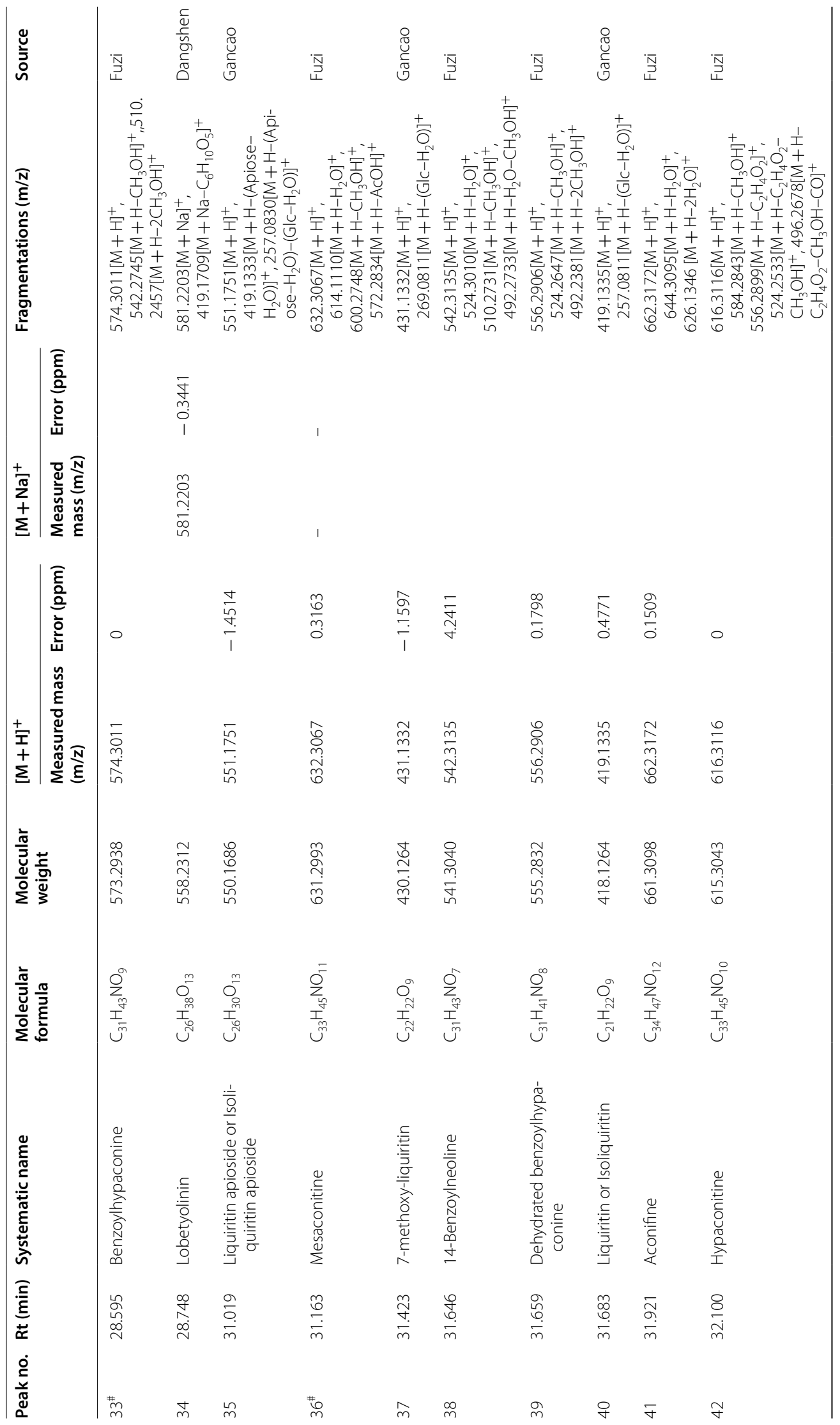




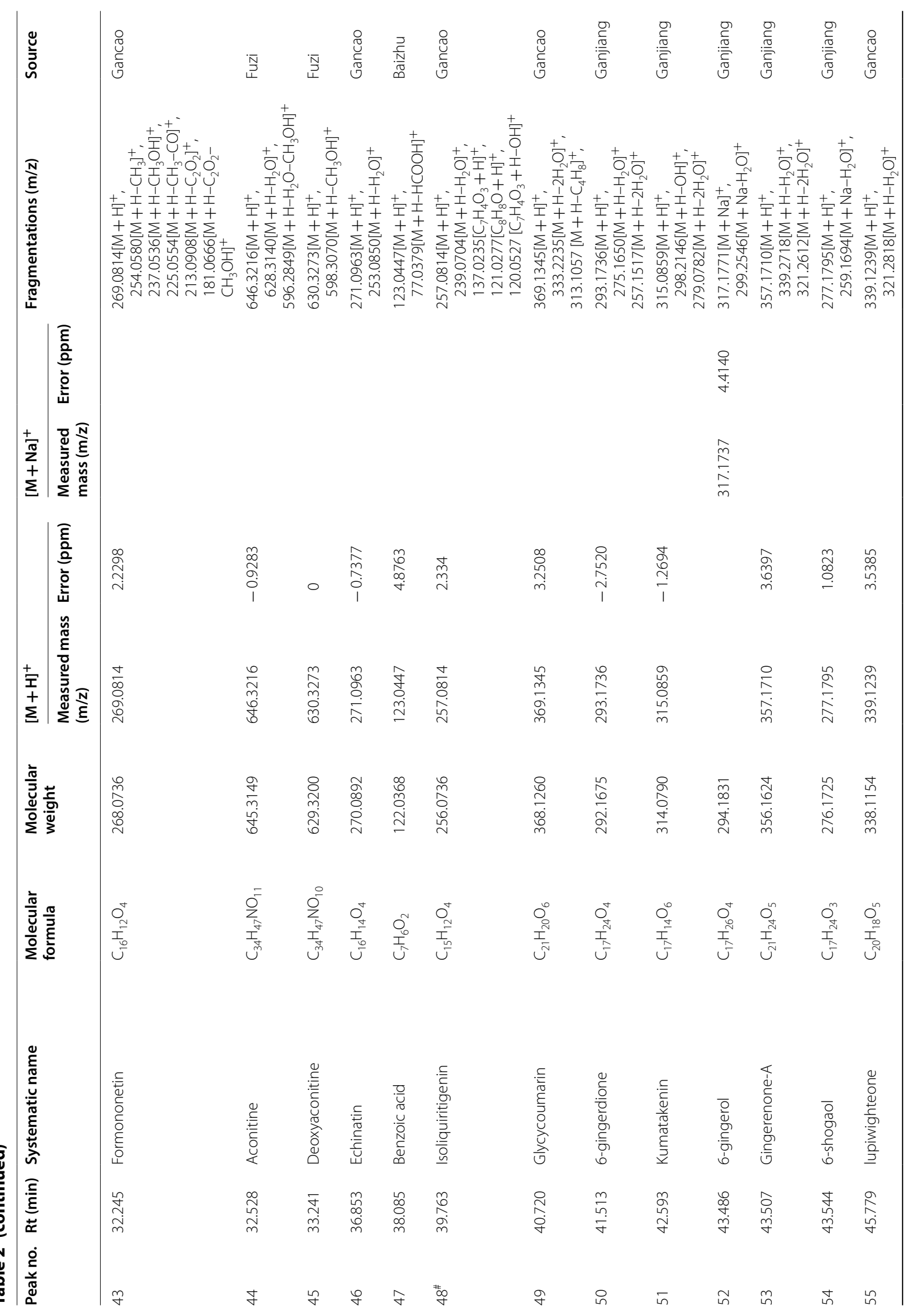




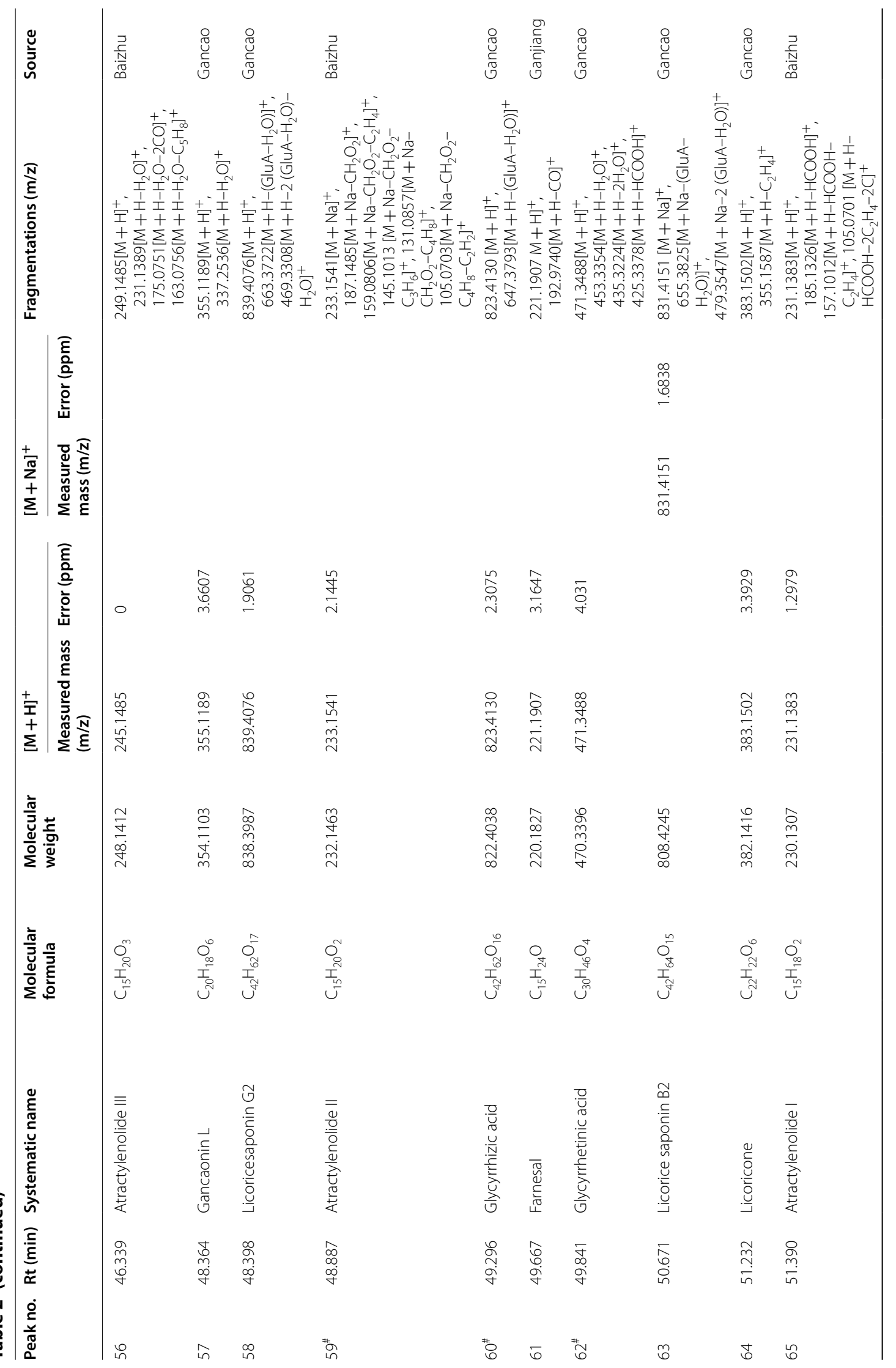




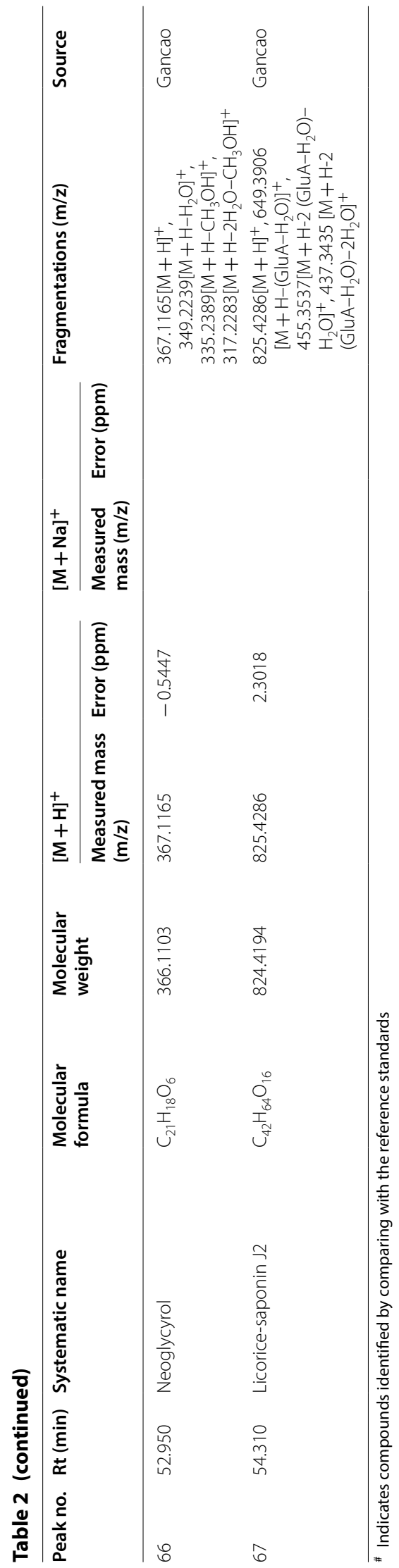


MS/MS data were shown as $\mathrm{m} / z$ of $239.0698[\mathrm{M}+\mathrm{H}-$ $\left.\mathrm{H}_{2} \mathrm{O}\right]^{+}, 137.0234\left[\mathrm{C}_{7} \mathrm{H}_{4} \mathrm{O}_{3}+\mathrm{H}\right]^{+}, 121.0293\left[\mathrm{C}_{8} \mathrm{H}_{8} \mathrm{O}+\mathrm{H}\right]^{+}$ and $120.0721\left[\mathrm{C}_{7} \mathrm{H}_{4} \mathrm{O}_{3}+\mathrm{H}-\mathrm{OH}\right]^{+}$. And the compound 29 in Table 2 were detected in the positive ion mode at the Rt in $24.785 \mathrm{~min}$ with the $m / z$ of $257.0819\left(\mathrm{C}_{15} \mathrm{H}_{13} \mathrm{O}_{4}\right)$, $239.0707\left[\mathrm{M}+\mathrm{H}-\mathrm{H}_{2} \mathrm{O}\right]^{+}$and $137.0235\left[\mathrm{C}_{7} \mathrm{H}_{4} \mathrm{O}_{3}+\mathrm{H}\right]^{+}$. Then compound 29 were characterized as liquiritigenin. Similar to the identification process above, among 67 compounds, 9 compounds were identified as benzoylaconine, benzoylmesaconine, benzoylhypaconine, mesaconitine, liquiritigenin, isoliquiritigenin, glycyrrhizic acid, glycyrrhetinic acid and atractylenolide II. The MS data of the (+) ESI-MS spectra are shown in Table 2.

The remaining 58 compounds were tentatively characterized based on their chromatographic and spectrometric data, referring to previous literature [25, 30-33]. For example, $\mathrm{MS}^{2}$ spectra of compound 4 (molecular ion at $\left.m / z[\mathrm{M}+\mathrm{H}]^{+} 394.2590\right)$ in Table 2 gave characteristic fragment ions of $\left[\mathrm{M}+\mathrm{H}-\mathrm{H}_{2} \mathrm{O}\right]^{+}$at $\mathrm{m} / z 376.2489$ and $\left[\mathrm{M}+\mathrm{H}-2 \mathrm{H}_{2} \mathrm{O}\right]^{+}$at $m / z$ 358.2371. Thus, it corresponded to Karakolidine by comparison with literature data [30]. Moreover, $\mathrm{MS}^{2}$ spectra of compound 12 (molecular ion at $\left.m / z[\mathrm{M}+\mathrm{H}]^{+} 408.2743\right)$ in Table 2 gave characteristic fragment ions of $\left[\mathrm{M}+\mathrm{H}-\mathrm{H}_{2} \mathrm{O}\right]^{+}$at $m / z 390.2630$, $372.2517\left[\mathrm{M}+\mathrm{H}-2 \mathrm{H}_{2} \mathrm{O}\right]^{+}$and $\left[\mathrm{M}+\mathrm{H}-\mathrm{CH}_{3} \mathrm{OH}\right]^{+}$at $\mathrm{m} / z$ 358.2374. Then it was identified as Isotalatizidine. All the MS data of the (+) ESI-MS spectra are shown in Table 2. Besides, all the structures of the compounds identified are shown in Figs. 3 and 4. The deriving herb for each compound was also assigned. The majority of constituents are identified as alkaloids, flavonoids, triterpenes, gingerols, phenylpropanoids and volatile oil.

\section{Characterization of the absorbed chemical constituents in rat serum \\ Identification of the bioactive chemical prototype constituents in rat serum}

As the results of constituents in rat serum show in Table 3 , by comparing the $t_{R}$ values and MS fragment characteristics between compounds in serum and compounds in FZLZP extract, 10 alkaloid components sourced from Aconitum carmichaeli Debx. were identified, including benzoylaconine, benzoylmesaconine, benzoylhypaconine, mesaconitine, Hypaconitine, fuziline, neoline, talatisamine, chasmanine, and 14-acetyltalatizamine. These constituents have been reported as parts of the main constituents with significant effects of analgesia, anti-inflammation, thermogenesis and increasing blood oxygen in Fuzi $[34,35]$. The MS data of the $(+)$ ESI-MS spectra are shown in Table 3. For example, MS ${ }^{2}$ spectra of compound 19 in Table 2 was detected at the Rt in $16.070 \mathrm{~min}$ with the molecular ion at $m / z 454.2800[\mathrm{M}+\mathrm{H}]^{+}$and gave characteristic fragment ions of $\left[\mathrm{M}+\mathrm{H}-\mathrm{H}_{2} \mathrm{O}\right]^{+}$at $m / z$ 436.2677. Similarly, $\mathrm{MS}^{2}$ spectra of compound 2 in Table 3 was detected at the Rt in $16.615 \mathrm{~min}$ with the molecular ion at $\mathrm{m} / \mathrm{z}$ $454.2808[\mathrm{M}+\mathrm{H}]^{+}$and gave characteristic fragment ions of $\left[\mathrm{M}+\mathrm{H}-\mathrm{H}_{2} \mathrm{O}\right]^{+}$at $m / z 436.0243$. Thus, compound 2 in Table 3 was identified as the absorbed prototype of Fuziline in rat serum. The other alkaloid components were identified in a similar way.

Six compounds sourced from Glycyrrhiza uralensis Fisch. were identified, including 3 flavonoids, namely, liquiritigenin, isoliquiritigenin, and formononetin and 2 triterpenes, namely, glycyrrhetinic acid and glycyrrhizic acid. The MS data of the (+)ESI-MS spectra are shown in Table 3. For example, $\mathrm{MS}^{2}$ spectra of compound 48 in Table 2 was detected at the Rt in $39.763 \mathrm{~min}$ with the molecular ion at $\mathrm{m} / z 257.0814[\mathrm{M}+\mathrm{H}]^{+}$and gave characteristic fragment ions of 239.0704[ $\mathrm{M}+\mathrm{H}-$ $\left.\mathrm{H}_{2} \mathrm{O}\right]^{+}, 137.0235\left[\mathrm{C}_{7} \mathrm{H}_{4} \mathrm{O}_{3}+\mathrm{H}\right]^{+}, 121.0277\left[\mathrm{C}_{8} \mathrm{H}_{8} \mathrm{O}+\mathrm{H}\right]^{+}$, $120.0527\left[\mathrm{C}_{7} \mathrm{H}_{4} \mathrm{O}_{3}+\mathrm{H}-\mathrm{OH}\right]^{+}$. Similarly, $\mathrm{MS}^{2}$ spectra of compound 14 in Table 3 was detected at the Rt in $40.710 \mathrm{~min}$ with the molecular ion at $\mathrm{m} / \mathrm{z}$ $257.0807[\mathrm{M}+\mathrm{H}]^{+}$and gave characteristic fragment ions of $\left[\mathrm{M}+\mathrm{H}-\mathrm{H}_{2} \mathrm{O}\right]^{+}$at $m / z$ 239.1624. Thus, compound 14 in Table 3 was identified as the absorbed prototype of Isoliquiritigenin in rat serum. Furthermore, liquiritin or isoliquiritin may also have been found, but further comparison with reference compounds is needed to identify these isomers. The flavonoids and triterpenes in Glycyrrhiza uralensis Fisch. have been reported as having significant anti-inflammatory, abirritation and immunoregulation effects [36-38].

7-Hydroxycoumarin, atractylenolide I and atractylenolide II have been identified as bioactive chemical constituents sourced form Atractylodes macrocephala Koidz. (Baizhu) and were found as the main institutes with the effect of anti-inflammatory, antitumor and gastrointestinal regulation in Baizhu [39-42]. The MS data of the (+) ESI-MS spectra are shown in Table 3. For example, $\mathrm{MS}^{2}$ spectra of compound 26 in Table 2 was detected with the molecular ion at $m / z 163.0395[\mathrm{M}+\mathrm{H}]^{+}$and gave characteristic fragment ions of $145.0627\left[\mathrm{M}+\mathrm{H}-\mathrm{H}_{2} \mathrm{O}\right]^{+}$. Similarly, $\mathrm{MS}^{2}$ spectra of compound 25 in Table 3 was detected with the molecular ion at $m / z 163.0396[\mathrm{M}+\mathrm{H}]^{+}$ and gave characteristic fragment ions of $\left[\mathrm{M}+\mathrm{H}-\mathrm{H}_{2} \mathrm{O}\right]^{+}$ at $m / z$ 145.5012. Thus, compound 25 in Table 3 was identified as the absorbed prototype of 7-hydroxycoumarin in rat serum.

6-Gingerdione, 6-gingerol and 6-shogaol sourced from Zingiber officinale Rosc (Ganjiang) were identified and were reported as having obvious antioxidant, anti-inflammatory, gastrointestinal protective and antitumor effects $[43,44]$. The MS data of the (+) ESI-MS spectra are shown in Table 3. For example, $\mathrm{MS}^{2}$ spectra of compound 


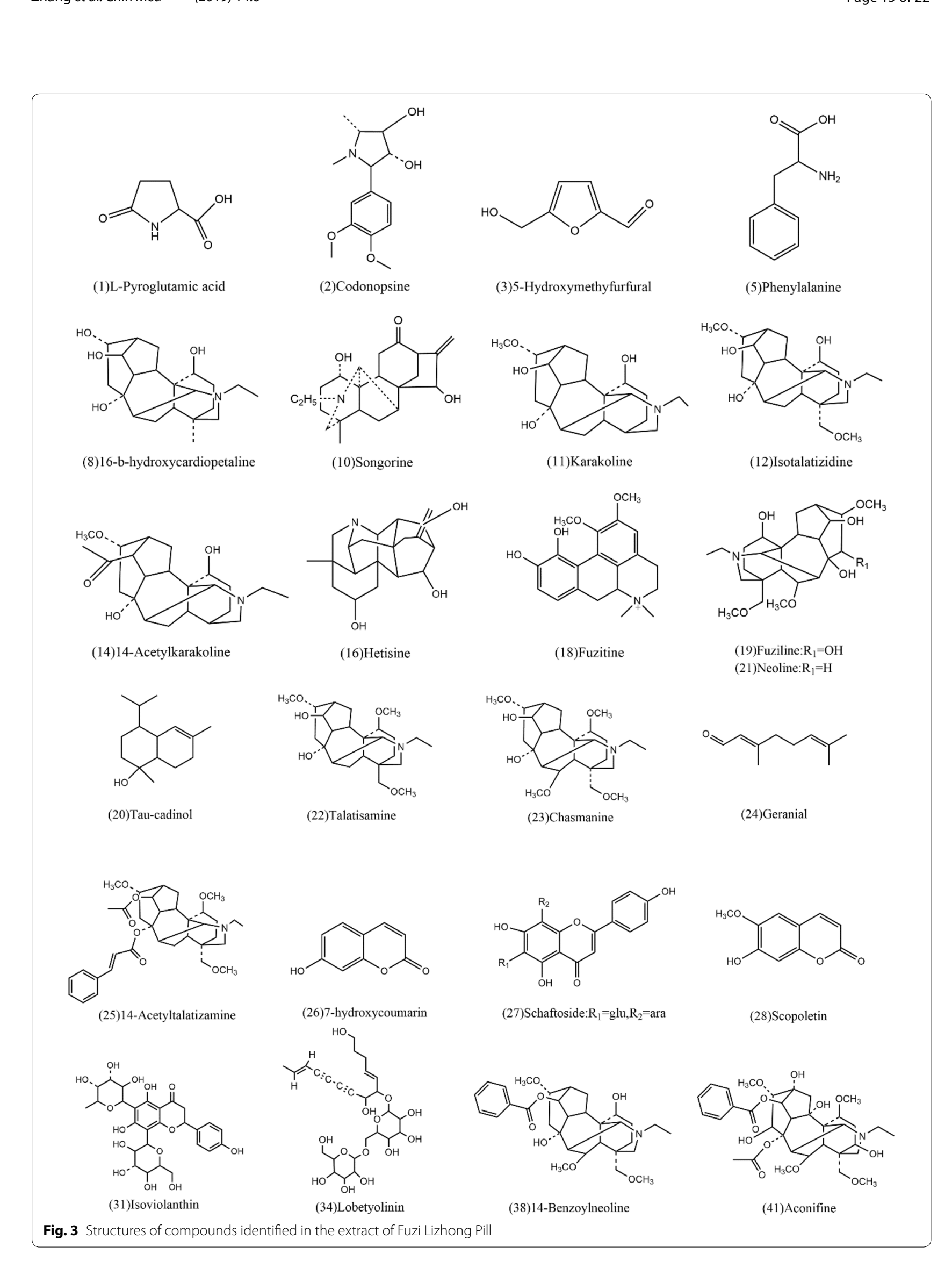


Zhang et al. Chin Med

(2019) $14: 6$

Page 16 of 22

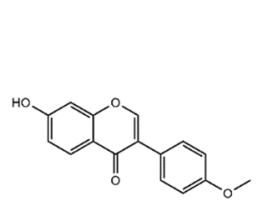

(43)Formononetin

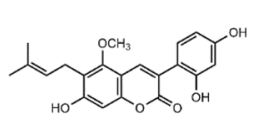

(49)Glycycoumarin

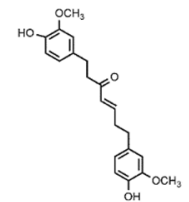

(53)Gingerenone-A

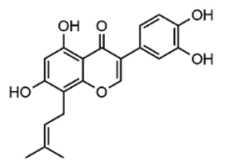

(57)Gancaonin L

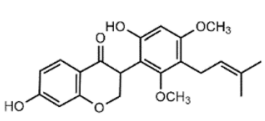

(64)Licoricone

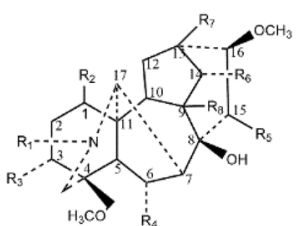

(4) Karakolidine: $\mathrm{R}_{1}=\mathrm{C}_{2} \mathrm{H}_{9}, \mathrm{R}_{2}=\mathrm{R}_{6}=\mathrm{OH}, \mathrm{R}_{3}=\mathrm{R}_{4}=\mathrm{R}_{5}=\mathrm{R}_{7}=\mathrm{R}_{8}=\mathrm{H}$

(6) Senbusine $\mathrm{A}: \mathrm{R}_{1}=\mathrm{C}_{2} \mathrm{H}_{5}, \mathrm{R}_{2}=\mathrm{R}_{4}=\mathrm{R}_{6}=\mathrm{OH}, \mathrm{R}_{3}=\mathrm{R}_{5}=\mathrm{R}_{7}=\mathrm{R}_{8}=$

(7) 9-OH-Senbusine $A: \mathrm{R}_{1}=\mathrm{C}_{2} \mathrm{H}_{5}, \mathrm{R}_{2}=\mathrm{R}_{4}=\mathrm{R}_{6}=\mathrm{R}_{8}=\mathrm{OH}, \mathrm{R}_{3}=\mathrm{R}_{5}=\mathrm{R}_{7}=\mathrm{H}$

(13) Senbusine $B . \mathrm{R}_{1}-\mathrm{C}_{2} \mathrm{H}_{5}, \mathrm{R}_{2}-\mathrm{R}_{5}-\mathrm{R}_{6}=\mathrm{OH}, \mathrm{R}_{3}-\mathrm{R}_{4}=\mathrm{R}_{7}=\mathrm{R}_{8}=\mathrm{H}$

(32)Benzoylaconine: $\mathrm{R}_{1}=\mathrm{C}_{2} \mathrm{H}_{5}, \mathrm{R}_{2}=\mathrm{R}_{4}=\mathrm{OCH}_{3}, \mathrm{R}_{3}=\mathrm{R}_{5}=\mathrm{R}_{7}=\mathrm{OH}, \mathrm{R}_{6}=\mathrm{OB} 7 \mathrm{R}_{8}=\mathrm{H}$

(33) Benzoyllhypaconine: $\mathrm{R}_{1}=\mathrm{CH} 3, \mathrm{R}_{2}=\mathrm{R}_{4}=\mathrm{OCH}, \mathrm{R}_{3}=\mathrm{R}_{8}=\mathrm{H}, \mathrm{R}_{5}=\mathrm{R}_{7}=\mathrm{OH}, \mathrm{R}_{6}=\mathrm{OB}$ \%

(39)Dehydrated Benzoyllyypaconine: $\mathrm{R}_{1}=\mathrm{CH} 3, \mathrm{R}_{2}=\mathrm{R}_{4}=\mathrm{OCH}_{3}, \mathrm{R}_{3}=\mathrm{H}, \mathrm{R}=\mathrm{OH}, \mathrm{R}_{6}=\mathrm{OB}$

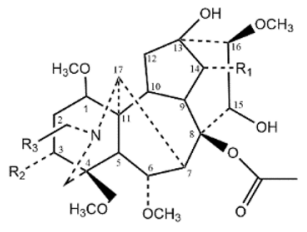

(36)Mesaconitine: $\mathrm{R}_{1}=\mathrm{OBz}, \mathrm{R}_{2}=\mathrm{OH}, \mathrm{R}_{3}=\mathrm{H}$

(42)Hypaconitine: $\mathrm{R}_{1}=\mathrm{OBz}, \mathrm{R}_{2}=\mathrm{H}, \mathrm{R}_{3}=\mathrm{H}$

(44)Aconitine: $\mathrm{R}_{1}=\mathrm{OBz}, \mathrm{R}_{2}=\mathrm{OH}, \mathrm{R}_{3}=\mathrm{CH} 3$
(45)Deoxyaconitine: $\mathrm{R}_{1}=\mathrm{OBz}, \mathrm{R}_{2}=\mathrm{H}, \mathrm{R}_{3}=\mathrm{CH}$

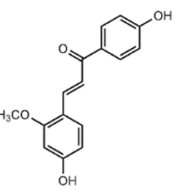

(46)Echinatin
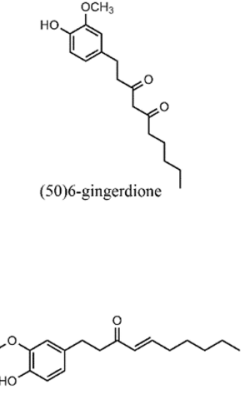

(54)6-shogaol

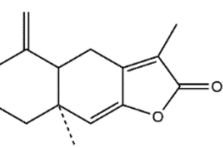

(59)Atractylenolide II

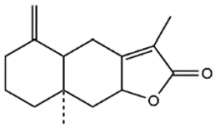

65) Atractylenolide

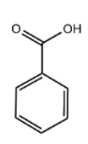

(47)Benzoic acid

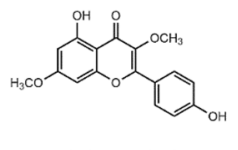

(51)Kumatakenin

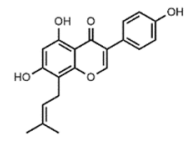

(55)Lupiwighteone

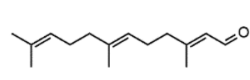

(61)Farnesal

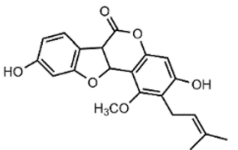

(66) Neoglycyrol

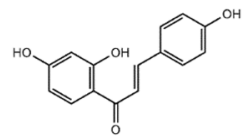

(48)Isoliquiritigenin

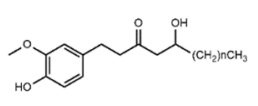

(52)6-gingerol $n=4$

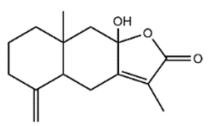

(56)Atractylenolide III

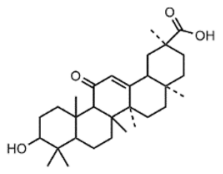

(62)Glycymhetinic acid
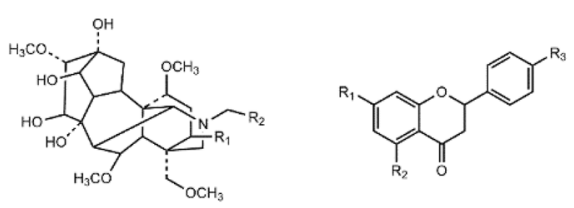

(9)Mesaconine: $\mathrm{R} 1=\mathrm{OH}, \mathrm{R} 2=\mathrm{H}$

(15) Aconine: $\mathrm{R} 1=\mathrm{OH}, \mathrm{R} 2=\mathrm{CH} 3$

(29) Liquiritigenin: $\mathrm{R}_{1}=\mathrm{R}_{3}=\mathrm{OH}, \mathrm{R}_{2}=\mathrm{H}$

(37) 7-methoxy-liquiritin: $\mathrm{R}_{1}=\mathrm{OCH}_{3}, \mathrm{R}_{2}=\mathrm{H}, \mathrm{R}_{3}=-\mathrm{O}$-glu

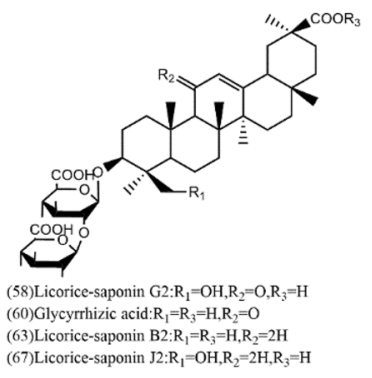

Fig. 4 Structures of compounds identified in the extract of Fuzi Lizhong Pill 


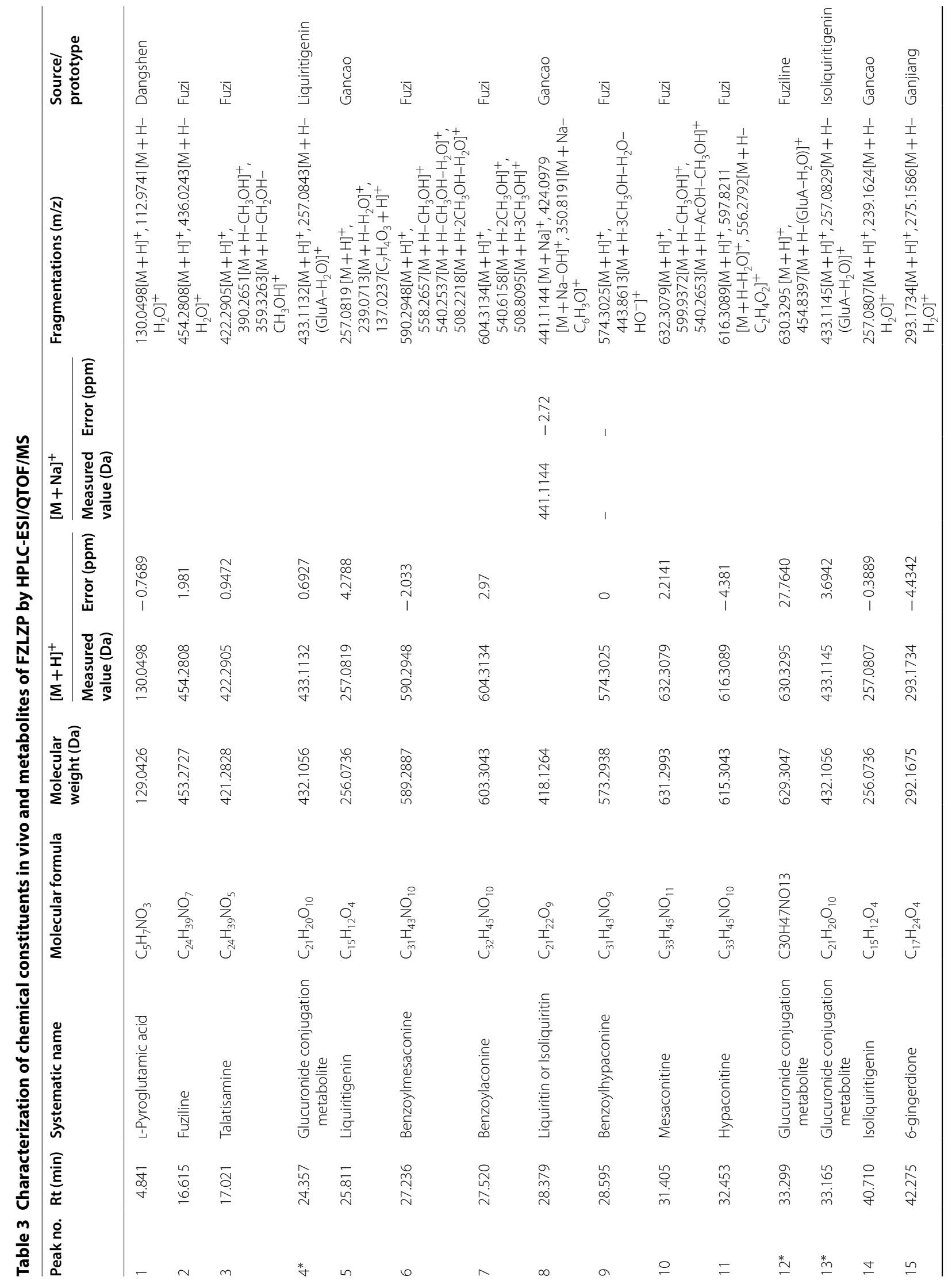


Chang et al. Chin Med $\quad$ (2019) 14:6

Page 18 of 22

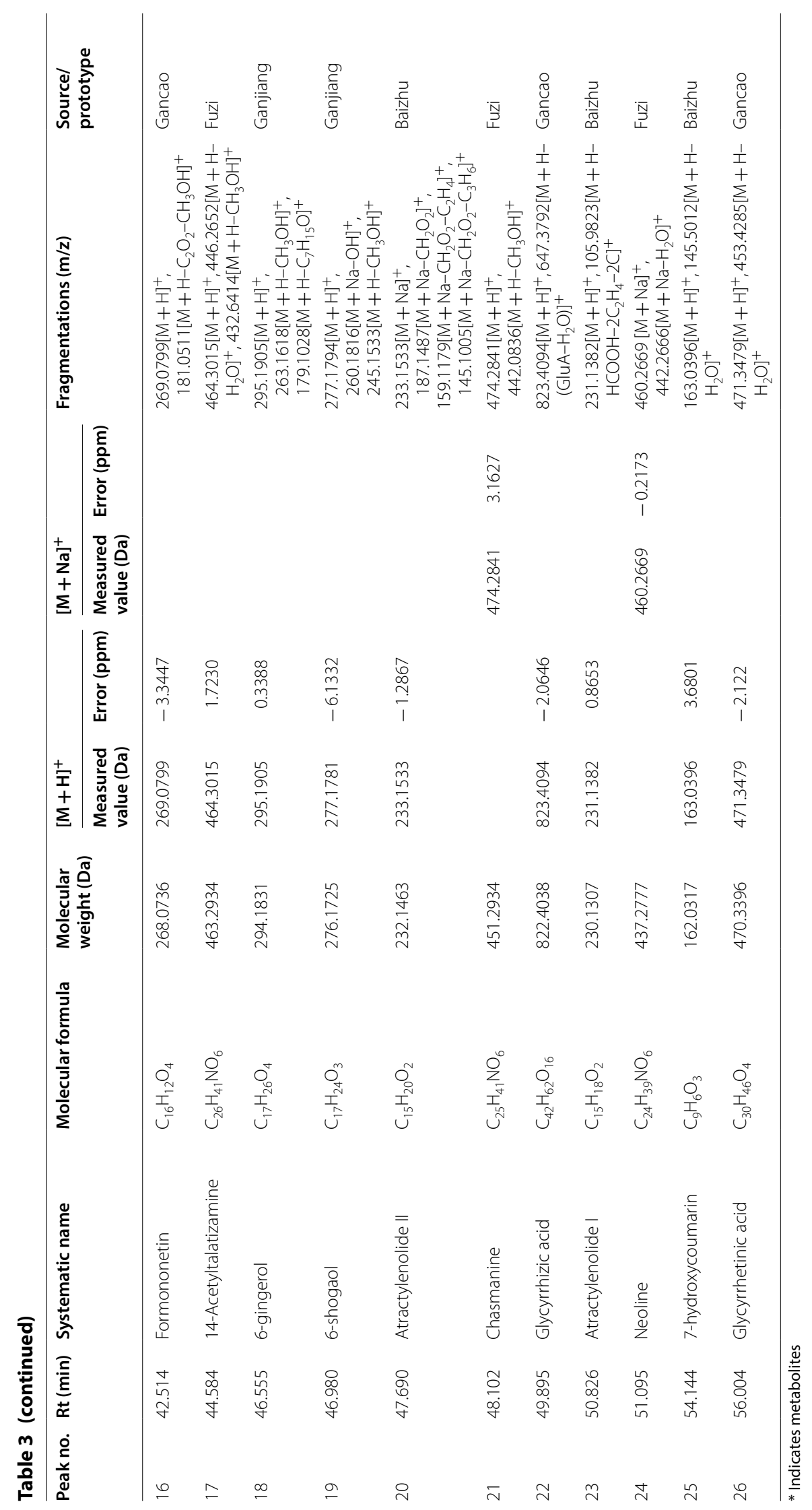


50 in Table 2 was detected with the molecular ion at $\mathrm{m} / z$ $293.1736[\mathrm{M}+\mathrm{H}]^{+}$and gave characteristic fragment ions of $275.1650\left[\mathrm{M}+\mathrm{H}-\mathrm{H}_{2} \mathrm{O}\right]^{+}, \quad 257.1517\left[\mathrm{M}+\mathrm{H}-2 \mathrm{H}_{2} \mathrm{O}\right]^{+}$. Similarly, $\mathrm{MS}^{2}$ spectra of compound 15 in Table 3 was detected with the molecular ion at $m / z 293.1734[\mathrm{M}+\mathrm{H}]^{+}$ and gave characteristic fragment ions of $\left[\mathrm{M}+\mathrm{H}-\mathrm{H}_{2} \mathrm{O}\right]^{+}$ at $m / z 257.1586$. Thus, compound 15 in Table 3 was identified as the absorbed prototype of 6-gingerdione in rat serum.

One compound was sourced from Codonopsis pilosula (Franch.) Nannf. (Dangshen) and was identified as L-pyroglutamic acid. $\mathrm{MS}^{2}$ spectra of compound 1 in Table 2 was detected with the molecular ion at $\mathrm{m} / \mathrm{z}$ $130.0505[\mathrm{M}+\mathrm{H}]^{+}$and gave characteristic fragment ions of $112.0123\left[\mathrm{M}+\mathrm{H}-\mathrm{H}_{2} \mathrm{O}\right]^{+}, 84.0449[\mathrm{M}+\mathrm{H}-\mathrm{HCOOH}]^{+}$. Similarly, $\mathrm{MS}^{2}$ spectra of compound 1 in Table 3 was detected with the molecular ion at $m / z 130.0498[\mathrm{M}+\mathrm{H}]^{+}$ and gave characteristic fragment ions of $\left[\mathrm{M}+\mathrm{H}-\mathrm{H}_{2} \mathrm{O}\right]^{+}$ at $m / z 112.9741$. Thus, compound 1 in Table 3 was identified as the absorbed prototype of L-pyroglutamic acid in rat serum.

\section{Identification of the bioactive metabolites in rat serum}

Based on a comparison of the information for ions, 8 peaks were detected only in dosed serum and were assigned to metabolites. Detailed information about the elemental compositions, retention times, and the characteristic fragment ions of metabolites are shown in Table 3. Alkaloid-, phenylpropanoids- and gingerolsrelated metabolites are the main metabolic constituents of FZPLP absorbed in vivo, and the main metabolic pathways in vivo were glucuronide conjugation and glucuronide. Identification of the corresponding fragment ions was obvious. For example, compound 4 (24.357 $\mathrm{min})$ in Table 3 produced $[\mathrm{M}+\mathrm{H}]+$ at $m / z 433$ and $\mathrm{MS}^{2}$ yielded a major ion at $m / z 257\left(-176\right.$, Da with the loss of $\left.\mathrm{C}_{6} \mathrm{H}_{8} \mathrm{O}_{6}\right)$ in the positive ion mode, combined with the retention time of the reference standard 1 in Table 1 and compound 29 in Table 2 . Therefore, the peak was identified tentatively as a glucuronide conjugation metabolite of liquiritigenin. Similarly, compound 13 (the $t_{R} 33.165 \mathrm{~min}$ ) in Table 3 has the similar retention time compared with the reference standard 6 in Table 1 and compound 48 in Table 2. And it produced $[\mathrm{M}+\mathrm{H}]+$ at $m / z 433$ and $\mathrm{MS}^{2}$ yielded a major ion at $m / z 257(-176$, Da with the loss of $\mathrm{C}_{6} \mathrm{H}_{8} \mathrm{O}_{6}$ ) in the positive ion mode. Therefore, the peak was identified tentatively as a glucuronide conjugation metabolite of isoliquiritigenin. The possible structures of metabolites were elucidated as described above. All of the structures of metabolites were identified, and the MS data of the (+) ESI-MS spectra are shown in Table 3. This article reports these metabolites of FZLZP for the first time. The bioactivities are the subject of ongoing research.

\section{Alkaloids difference between Group A and Group B}

As the result shows in Fig. 5a, 10 kinds of alkaloids were detected in Group A. Most of them were trace amounts in vivo, which indicated the alkaloids' poor absorption in the prescription. Conversely, unlike Group A, the amount of the alkaloids in vivo increased obviously in Group B (Fig. 5b). The difference indicated that the absorption amount of alkaloids in the prescription can be decreased compared to the absorption amount of alkaloids in the herb powder.

\section{Discussion}

To obtain LC chromatograms of lower pressure, greater baseline stability, better resolution and higher ionization efficiency, methanol and acetonitrile and series of concentrations of aqueous formic acid solution were prepared for analysis. The best result was achieved when the mobile phase consisted of $0.1 \%$ formic acid aqueous solution and methanol. Both positive and negative modes were investigated, and the results showed that the positive ion mode was more sensitive and could provide more information for both extract samples and serum samples analyses.

FZLZP is a formula composed under the guidance of traditional Chinese medicine theory. According to TCM theory, Aconitum carmichaeli Debx. is the "monarch drug" and the main herb in FZLZP recipe to warm middle jiao and eliminate cold. This was confirmed in this research with 10 constituents among 23 prototype components sourced from Aconitum carmichaeli Debx., which maintains the maximum bioactive compounds. Glycyrrhiza uralensis Fisch. is frequently prescribed in combination with other herbs to decrease toxicity and to increase efficacy. In this recipe, it is the "envoy drug" and is considered to be the paramount assistant herb, which can detoxify the toxicity of aconitum. In this study, we found that Glycyrrhiza uralensis Fisch. was the second most-absorbed herb. The results that some compounds absorbed well in vivo derived from Aconitum carmichaeli Debx. and Glycyrrhiza uralensis Fisch. are consistent with our previous studies that they were dissolved very well in vitro [16].

Alkaloids in Fuzi herb are the toxicity as well as the efficacy compounds. The prescriptions which contains Fuzi herb should be highly concerned. In our study, the results on the differences in alkaloids between Group A and Group B show that the amount of absorption of bioactive constituents in Fuzi can be significantly reduced when this herb is used as part of a prescription rather than used alone. We think there are two reasons. 

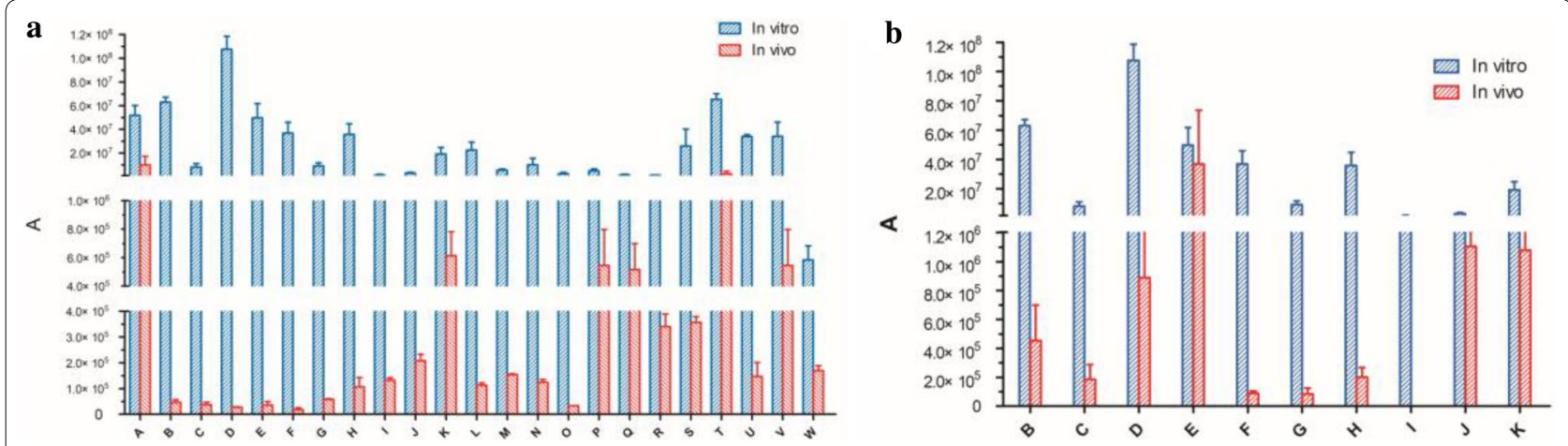

Fig. 5 The difference in the absorbed compounds in vitro and in vivo. (a The difference in the absorbed compounds in vitro and in vivo of Group A; b The difference in the absorbed alkaloids in vitro and in vivo of Group B.) (Columns: A, L-pyroglutamic acid; B, Fuziline; C, Talatisamine; D, Benzoylmesaconine; E, Benzoylaconine; F, Benzoylhypaconine; G, Mesaconitine; H, Hypaconitine; I, 14-Acetyltalatizamine; J, Chasmanine; K, Neoline; L, Liquiritigenin; M, Liquiritin or Isoliquiritin; N, Isoliquiritigenin; O, Formononetin; P, Glycyrrhizic acid; Q, Glycyrrhetinic acid; R, 6-gingerdione; S, 6-gingerol; T, 6-shogaol; U, Atractylenolide II; V, Atractylenolide I; W, 7-hydroxycoumarin)

Firstly, according to the TCM theory, the toxicity of Fuzi can be reduced in combination with Gancao [25]. This should be further confirmed by researching the relationship and differences in the chemistry constituents between Fuzi-Gancao herb pairs in FZLZP. Secondly, the pill form is the embryonic form of sustained-release preparations. As a TCM classic says: only pill among all dosage forms can reduce the toxicity of toxic drugs. The toxic herb was usually made into a pill form to reduce the toxicity in TCM [17]. And it can be further confirmed by researching differences in the chemistry constituents between FZLZP and the Fuzi pill that made from Aconitum carmichaeli Debx. powder.

\section{Conclusions}

This study describes a simple, sensitive and selective HPLC-QTOF-MS method for structural characterization of chemical constituents in FZLZP and bioactive components in rat serum following oral administration of FZLZP. As a result, in vitro, a total of 67 compounds were successfully identified, and 23 prototype compounds that were absorbed in vivo were identified for the first time. In addition, 3 metabolites of the bioactive compounds were tentatively identified. In this prescription, the majority of compounds absorbed in vivo derived from Fuzi and Gancao. The results provide helpful chemical information for FZLZP for further pharmacological and active mechanism research. In addition, it helped to classify the material basis responsible for the therapeutic effects of FZLZP. Furthermore, the HPLC-QTOF-MS was a potentially powerful strategy for simultaneously achieving screening and analysis of multiple bioactive compounds in FZLZP.

\section{Additional file}

Additional file 1. Minimum standards of reporting checklist.

\section{Abbreviations}

HPLC-QTOF-MS: high-performance liquid chromatography-electrospray ionization/quadrupole-time-of-flight high-definition mass spectrometry; FZLZP: Fuzi Lizhong Pill; FZP: Fuzi powder; Group A: FZLZP group for dosed rat serum; Group B: Fuzi powder group for dosed rat serum; Group C: control group for blank rat serum.

\section{Authors' contributions}

$\mathrm{ZZ}$ and $\mathrm{MJ}$ carried out the screening experiments, ZZ wrote the manuscript and analyzed the data, MJ, XW, SY, JS graphed the picture, GZ revised the manuscript, CF and LG conceived of the study, contributed to the design and interpretation of the research. All authors read and approved the final manuscript.

\section{Author details}

${ }^{1}$ The Ministry of Education Key Laboratory of Standardization of Chinese Herbal Medicine, State Key Laboratory Breeding Base of Systematic Research, Development and Utilization of Chinese Medicine Resources, College of Pharmacy, Chengdu University of Traditional Chinese Medicine, Chengdu 611137, China. ${ }^{2}$ Sichuan Institute for Food and Drug Control, Chengdu 611137, China.

\section{Acknowledgements}

Not applicable.

\section{Competing interests}

The authors declare that they have no competing interests.

\section{Availability of data and materials}

The dataset supporting the conclusions of this article is included within the article.

\section{Consent for publication}

Not applicable.

Ethics approval and consent to participate

Not applicable.

\section{Funding}

This work was supported by the National Natural Science Foundation of China (No. 81803742), Key Project of Natural Science Fund of Sichuan Province (No. 
18ZA0187), Pre-research National Natural Science Foundation of Chengdu University of Traditional Chinese Medicine (No. ZRYY1718).

\section{Publisher's Note}

Springer Nature remains neutral with regard to jurisdictional claims in published maps and institutional affiliations.

Received: 7 November 2018 Accepted: 1 February 2019

Published online: 01 March 2019

\section{References}

1. Yang $X Y$. Investigation and analysis of clinical use of fuzi lizhong pills. Chin J Clinic Ratio Drug Use. 2018;11(10):98-100.

2. Yang $L L, X u Y Q$. Fuzi Lizhong Pill in the treatment of yang deficiency of spleen and kidney infantile anorexia. J GM Chin Med. 2018;33(12):1699-701.

3. Xu L, Zhao D. A randomized controlled study of fuzi lizhong pill combined with moxibustion in the treatment of severe enteral nutritional diarrhea. Cardi Disea J Integr Tradi Chin West Med. 2018;6(19):152-3.

4. Hu XL, Zhou H, Ning QY, Zhao ZX, Xu XS. Observation on the curative effect of the treatment of chronic terminal ileus of spleen and kidney Yang deficiency by the combined treatment of Fuzi-Lizhong Pill and heavy moxibustion. Guid J Tradit Chin Med Pharm. 2012;18(1):33-4.

5. Liu HL, Huang LX. Treating IBS with the Fuzi Lizhong wan plus bifico, aroxetine. Clin J Chin Med. 2015;7(13):71-3.

6. Hu LQ, Zhang LX, Zhang LF. Observation and analysis of the curative effect of fuzi lizhong pill combined with wuweita oral solution in the treatment of chronic ulcerative colitis. Med Innov Chin J. 2012;9(3):123-4.

7. Ye SH. The treatment of 62 cases of diarrhea irritable bowel syndrome by sishen pill combine with fuzi lizhong pill. SD J Tradi Chin Med. 2010;29(5):310-1.

8. Zhao X, Yang SJ, Zhang WT, Zu CZ, Tang BH, Zhang BC, et al. Fuzi-Lizhong pill compensates hypothyroid-hypothermia via ghrelin release. J Ethnopharmacol. 2013;149:707-12.

9. Dong LY, Cheng BF, Luo Y, Zhang N, Duan HQ, Jiang M, et al. Identification of nuclear factor- $\mathrm{kB}$ inhibitors and $\beta 2$ adrenergic receptor agonists in Chinese medicinal preparation Fuzilizhong Pills using UPLC with quadrupole time-of-flight MS. Phytochem Anal. 2014;25:113-21.

10. Zhao X, Wang Y, Yang SJ, Zhang WT, Zu ZC, Zhang TT, et al. Underlying mechanism of Aconitum Lizhong acting on experimental hypothermia with indigestion in rats: role of ghrelin. Evid Based Complement Alternat Med. 2012;2012:542461

11. Zhang WT, Tang HQ, Wang Y, Lu AN, Zhao X, Song M, et al. Aconitum Lizhong Pill strenthening adaptive thermogenesis in rats with spleen yang deficient syndrome. Chin Pharmac. 2010;13(7):918-21.

12. Zhang WT, Tang HQ, Lu AN, Wang XY, Luo J, Yang MJ, et al. Fuzi Lizhong Pills regulating myosin ATPase activity of skeletal muscle in rats with spleen yang deficient syndrome. Chin J Tradi Chin Med Pharm. 2011;26(3):490-4.

13. Tang HQ, Zhang WT, Lu A, Wang Y, Wang XY, Yang Y, et al. Effects of Aconitum Lizhong Pills on energy charge in skeletal muscle of rats with spleen yang deficiency syndrome. Chin Pharmac. 2010;13(12):1691-4.

14. Zhang WT, Tang HQ, Lu AN, Zhao X, Li GZ, Jiang YF, et al. Treatment with Aconitum Lizhong Pill down-regulates liver energy charge in rats with spleen yang deficiency syndrome. World Chin J Digest. 2010;18(35):3782-6.

15. Lu L, Tang HQ, Li XH, Zhu XY. Effects of Fuzi Lizhong Decoction on content of ANP, Expression of pGC mRNA and gastrointestinal dynamics in rats with spleen yang deficiency syndrome. Chin J Exp Tradit Med Form. 2013;19(24):264-6.

16. Jiang MY, Zhang Z, Shi JF, Zhang JM, Fu CM, Lin X, et al. Dissolution behavior of Fuzi Lizhong pill based on simultaneous determination of two components in Glycyrrhizae Radix et Rhizoma. Chin J Chin Mater Med. 2018;43(5):952-4.

17. Zhang Z, Gao TH, Fu CM, Zhang JM, Shi JF, He Y, et al. Analysis on dosage form theory and current application situation of traditional Chinese medicine pill. Chin J Chin Mater Med. 2017;42(12):2048.
18. Gao TH, Zhang Z, Zhang JM, Fu S, Fu CM. Research progress and comprehensive analysis of "toxicity and effect" of Fuzi Lizhong Pill. Pharm Clin Chin Mater Med. 2017;8(2):74-6.

19. Sun H, Wu F, Zhang A, Wei W, Han Y, Wang X. Profiling and identification of the absorbed constituents and metabolites of schisandra lignans by ultra-performance liquid chromatography coupled to mass spectrometry. Biomed Chromatogr. 2013;27:1511-9.

20. Wang $P$, Yin QW, Zhang AH, Sun H, Wu XH, Wang XJ. Preliminary identification of the absorbed bioactive components and metabolites in rat plasma after oral administration of Shaoyao-Gancao decoction by ultraperformance liquid chromatography with electrospray ionization tandem mass spectrometry. Pharmacogn Mag. 2014;10(40):497-502.

21. He JL, Zhao JW, Ma ZC, Wang YG, Liang QD, Tan HL, et al. Serum pharmacochemistry analysis using UPLC-Q-TOF/MS after oral administration to rats of Shenfu decoction. Evid Based Complement Alternat Med. 2015;2015:973930.

22. Sun H, Wu F, Zhang A, Wei W, Han Y, Wang X. Pharmacokinetic study of schisandrin, schisandrol B, schisantherin A, deoxyschisandrin, and schisandrin $B$ in rat plasma after oral administration of Shengmaisan formula by UPLC-MS. J Sep Sci. 2013;36:485-91.

23. Zeng HJ, Yang R, Guo C, Wang QW, Qu LB, Li JJ. Pharmacokinetic study of six flavones in rat plasma and tissues after oral administration of "JiangYaBiFeng" using SPE-HPLC-DAD. J Pharm Biomed Anal. 2011;56(4):815-9.

24. Zhang A, Sun $H$, Wang $X$, Jiao G, Yuan $Y$, Sun W. Simultaneous in vivo RP-HPLC-DAD quantification of multiple-component and drug-drug interaction by pharmacokinetics, using 6,7-dimethylesculetin, geniposide and rhein as examples. Biomed Chromatogr. 2012;26:844-50.

25. Zhang JM, Li L, Gao F, Li Y, He Y, Fu CM. Chemical ingredient analysis of sediments from both single Radix Aconiti Lateralis decoction and Radix Aconiti Lateralis-Radix Glycyrrhizae decoction by HPLC-MS. Acta Pharm Sin. 2012;47(11):1527-33.

26. Xue CS, Zhang AH, Sun H, Han Y, Zou D, Wang YY, et al. An improved ultra-performance liquid chromatography-electrospray ionization/ quadrupole-time-of-flight high-definition mass spectrometry method for determining ingredients of herbal Fructus corni in blood samples. Pharmacogn Mag. 2014;10(40):422-9.

27. Dong W, Wang P, Meng XC, Sun H, Zhang AH, Wang WM, et al. Ultraperformance liquid chromatography-high-definition mass spectrometry analysis of constituents in the root of Radix Stemonae and those absorbed in blood after oral administration of the extract of the crude drug. Phytochem Anal. 2012;23(6):657-67.

28. Wang SP, Zhang JZ, Zhang ZD, Gao WY, Yan YN, Li X, et al. Identification of chemical constituents in the extract and rat serum from Ziziphus Jujube Mill. by HPLC-PDA-ESI-MSn . Iran J Pharm Res. 2014;13(3):1055-63.

29. Li XN, Sun H, Zhang AH, Liu ZD, Zou D, Song YH, et al. High-throughput LC-MS method for the rapid characterization of multiple chemical constituents and metabolites of Da-Bu-Yin-Wan. J Sep Sci. 2017;40:4102-12.

30. Tan GG. Chemome and Metabonomics studied of traditional Chinese medicine Sini decoction. Second military medical university. Shanghai, China. 2012.

31. Huang XF, Ou YH, Li JM, Lu YJ, Li W, Gong QF. Identification of characteristic constituents in Atractylodis Macrocephalae Rhizoma from different regions by UPLC-Q-TOF-MS/MS. Chin J Exp Tradit Med Form. 2017; 23(23):27-33.

32. Hikino H, Konno C, Takata H, Yamada Y, Yamada C, Ohizumi Y, et al. Anti-inflammatory principles of Aconitum roots. J Pharm Dyn. 1980;3(10):514-25.

33. Zhang JM, Fu CM, He YX, Lu JR, Gao F, Wang JS. Comparison on chemical components in sediments of Aconiti Lateralis Radix Preparata-Glycyrrhizae Radix et Rhizoma before and after their compatibility. Chin Trad Herb Drug. 2013;44(2):165-9.

34. Makino T, Kato K, Mizukami H. Processed Aconite root prevents coldstress-induced hypothermia and immune-suppression in mice. Biol Pharm Bull. 2009;32(10):1741-8.

35. Chen S, Li WH, Chen XF, Liu M, Zhu ZY, Chai YF. Research progress of components and quality control analysis of alkaloids in Fuzi. Chin J Pharm Anal. 2014;34(10):1709-17.

36. Takami M, Tomohiro Y, Eiji T, Hiroaki S, Ikuo S, Tadato T. Pharmaceutical evaluation of liquorice before and after roasting in mice. J Pharm Pharmacol. 2010;56(5):589-95. 
37. Kim KR, Jeong CK, Park KK, Choi JH, Park JHY, Lim SS, et al. Anti-inflammatory effects of Licorice and roasted Licorice extracts on TPA-induced acute inflammation and collagen-induced arthritis in mice. J Biomed Biotechnol. 2010;2010:709378.

38. Ryoko S, Maiko O, Hiroko T, Kenzo O. Inhibitory effect of glycyrrhizin on the phosphorylation and DNA-binding abilities of high mobility group proteins 1 and 2. Biol Pharm Bull. 2001;24(8):906-11.

39. Li CQ, He LC, Dong HY, Jin JQ. Screening for the anti-inflammatory activity of fractions and compounds from Atractylodes macrocephala koidz. J Ethnopharmacol. 2007;114(2):212-7.

40. Wang CH, Duan HJ, He LC. Inhibitory effect of atractylenolide I on angiogenesis in chronic inflammation in vivi and in vitro. Eur J Pharmacol. 2009;612(1):143-52
41. Li CQ, He LC, Jin JQ. Atractylenolide I and Atractylenolide III inhibit lipopolysaccharide-induced TNF-a and no production in macrophages. Phytother Res. 2010;21(4):347-53.

42. Yang E, Zhong YM, Feng YF. Advance on the chemical constituents and pharmacological effects of Atractylodes macrocephala Koidz. J Guangdong Pharm Univ. 2012;28(2):219-21.

43. Yuki M, Hiroe K, Masashi H, Nobuji N. Antioxidant properties of gingerol related compounds from ginger. BioFactors. 2004;21:293-6.

44. Chrubasika S, Pittler MH, Roufogalis BD. Zingiberis rhizome: a comprehensive review on the ginger effect and efficacy profiles. Phytomedicine. 2005;12(9):684-701.
Ready to submit your research? Choose BMC and benefit from:

- fast, convenient online submission

- thorough peer review by experienced researchers in your field

- rapid publication on acceptance

- support for research data, including large and complex data types

- gold Open Access which fosters wider collaboration and increased citations

- maximum visibility for your research: over 100M website views per year

At BMC, research is always in progress.

Learn more biomedcentral.com/submissions 